\title{
A Quantitative Method for Groundwater Surveillance Monitoring Network Design at the Hanford Site
}

P. D. Meyer

December 1993

Prepared for the U.S. Department of Energy under Contract DE-AC06-76RLO 1830

Pacific Northwest Laboratory Operated for the U.S. Department of Energy by Battelle Memorial Institute 


\title{
DISCLAIMER
}

This report .vas prepared as an account of work sponsored by an agency of the United States Government. Neither the United States Government nor any agency thereof, nor Battelle Memorial Institute, nor any of their employees, makes any warranty, expressed or implied, or assumes any legal liability or responsibility for the accuracy, completeness, or usefulness of any information, apparatus, product, or process disclosed, or represents that its use would not infringe privately owned rights. Reference herein to any specific commercial product, process, or service by trade name, trademark, manufacturer, or otherwise does not necessarily constitute or imply its endorsement, recommendation, or favoring by the United States Government or any agency thereof, or Battelle Memorial institute. The views and opinions of authors expressed herein do not necessarily state or reflect those of the United States Government or any agency thereof.

\author{
PACIFIC NORTHWEST LABORATORY \\ operated by \\ BATTELLE MEMORIAL INSTITUTE \\ for the \\ UNITED STATES DEPARTMENT OF ENERGY \\ under Contract DE-ACO6-76RLO 1830
}

Printed in the United States of America

Available to DOE and DOE contractors from the

Office of Scientific and Technical Information, P.O. Box 62, Oak Ridge, TN 37831;

prices available from (615) 576-8401. FTS 626-8401.

Available to the public from the National rechnical Information Service,

U.S. Department of Commerce, 5285 Port Royal Rd., Springfield, VA 22161. 


\title{
A QUANTITATIVE METHOD FOR GROUNDWATER SURVEILANCE MONITORING NETWORK DESIGN AT THE HANFORD SITE
}

\author{
P. D. Meyer
}

December 1993

Prepared for

the U.S. Department of Energy

under Contract DE-ACO6-76RLO 1830

Pacific Northwest Laboratory

Richland, WA 99352 


\section{SUMMARY}

As part of the Environmental Surveillance Program at the Hanford Site, mandated by the U.S. Department of Energy, hundreds of groundwater wells are sampled each year, with each sample typically analyzed for a variety of constituents. The groundwater sampling program must satisfy several broad objectives. These objectives include an integrated assessment of the condition of groundwater and the identification and quantification of existing, emerging, or potential groundwater problems. This report explores the development of a quantitative network design method for the Groundwater Surveillance Project at the Hanford Site. The method presented attempts to generate network design alternatives that incorporate the stated concerns of the Groundwater Surveillance Project.

Several quantitative network design objectives are proposed and a mathematical optimization model is developed from these objectives. The model attempts to find minimum cost network alternatives that maximize the amount of information generated by the network. Information is measured both by the rate of change with respect to time of the conta inant concentration and the uncertainty in contaminant concentration. In an application to tritium monitoring at the Hanford Site, both information measures were derived from historical data using time series analysis. Results of the application illustrate that the optimization model captures several of the important groundwater surveillance concerns and can thus be used to evaluate current and proposed monitoring networks. However, several important concerns were clearly not represented in the model objectives. This demonstrates the necessity of defining objectives that $2=$ both quantifiable and explicitly related to stated concerns of the Groundwater Surveillance Project and the U.S. Department of Energy. Defining such objectives may be the most difficult task in the development of a quantitative network design method for the Groundwater Surveillance Project. 


\section{ACKNOWLEDGMENTS}

Several Pacific Northwest Laboratory staff members had a role in the research described in this document. Bob Bryce, manager of the Groundwater Surveillance Project at the Hanford Site during the execution of this research, is thanked both for his financial support and for his technical contributions to the development of the ideas expressed herein. John Evans provided the tritium

data used in the modeling and shared his unique perspective on the history of Hanford Site monitoring. Finally, Bill Webber provided significant assistance in the use of ARC/INFO to prepare some of the figures. 


\section{CONTENTS}

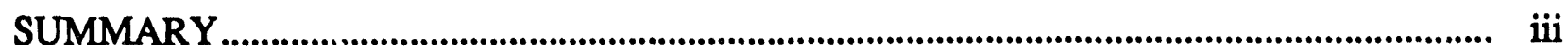

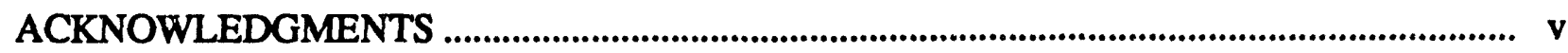

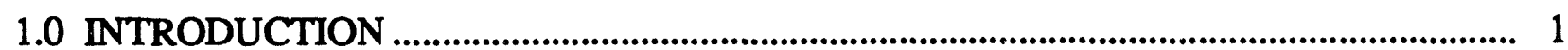

2.0 DEVELOPMENT OF A NETWORK DESIGN METHOD ............................................... 3

2.1 DEFINITION OF THE SYSTEM AND OBJECTIVES.................................................. 3

2.1.1 Quantifiable Objectives for Groundwater Surveillance...................................... 5

2.2 GENERATION AND EVALUATION OF NETWORK ALTERNATIVES................ 9

2.2.1 Construction of the Optimization Model .............................................................. 9

2.2.2 Determination of the Objective Function Coefficients...................................... 12

2.2.3 Solution of the Optimization Model ................................................................ 16

3.0 NETWORK OPTIMIZATION RESULTS ............................................................. 19

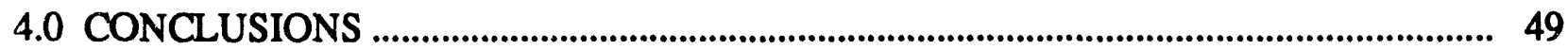

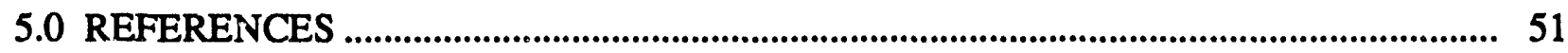




\section{FIGURES}

1 Hanford Site Map and Tritium Distribution Based on 1990 and 1989 Data..........................4

2 Measured Time Series for Well 699-1-18 and Its Equal Interval Approximation ............... 14

3 Spatial Subdomains for the Optimization Model ................................................................... 21

4 Contours of the Optimal Number of Samples Per Year as a Function of the Information Objectives - No Spatial Sampling Requirements .............................................. 22

5 Optimal Network Solution Emphasizing the Uncertainty Objective - No Spatial Sampling Requirementits .......................................................................................................... 25

6 Optimal Network Solution Emphasizing the Concentration Change Objective - No Spatial Sampling Requirements ................................................................................................ 27

7 Optimal Network Solution with Equal Emphasis on the Information Objectives - No Spatial Sampling Requirements

8 Contours of the Optimal Number of Samples Per Year as a Function of the Information Objectives - Includes Spatial Sampling Requirements

9 Optimal Network Solution Emphasizing the Uncertainty Objective - Includes Spatial Sampling Requirements

10 Optimal Network Solution Emphasizing the Concentration Change Objective Includes Spatial Sampling Requirements

11 Representative Hanford Site Surveillance Monitoring Network Consisting of 264 Samples from 163 Locations

12 Contours of the Number of Samples as a Function of the Information Objectives Includes Spatial Sampling Requirements....

13 Optimal Network Solution Emphasizing the Concentration Change Objective Includes Spatial Sampling Requirements.. 43

14 Optimal Network Solution Emphasizing the Concentration Change Objective Includes Spatial Sampling Requirements 


\subsection{INTRODUCTION}

As part of the Hanford Site Groundwater Protection Management Program, groundwater monitoring is carried out to ensure compliance with the Resource Conservation and Recovery Act (RCRA) and the Comprehensive Environmental Response, Compensation, and Liability Act (CERCLA) and to ensure compliance with U.S. Department of Energy (DOE) operational requirements. In addition, Pacific Northwest Laboratory ${ }^{(a)}$ performs groundwater monitoring independently of the compliance monitoring as part of the Environmental Surveillance Program. The surveillance program was established in response to DOE Order 5400.1 (DOE 1988), which requires an assessment of the impact of DOE activities at the Hanford Site on the onsite and the offsite environment. DOE Order 5400.1 states that surveillance monitoring shall be designed to satisfy one or more of the following objectives (Bryce et al. 1991): verify compliance with applicable environmental laws and regulations; verify compliance with environmental commitments made in environmental impact statements, environmental assessments, safety analysis reports, or other official DOE documents; characterize and define trends in the physical, chemical, and biological condition of environmental media; establish baselines of environmental quality; provide a continuing assessment of pollution abatement programs; and identify and quantify new or e:isting enviromental quality problems.

In consultation with DOE, these objectives have been modified to apply specifically to the Groundwater Surveillance Project at the Hanford Site. Four objectives have been identified (Bryce et al. 1991).

1. Identify and quantify existing, emerging, or potential groundwater quality problems.

2. Review all groundwater quality data gathered on the Hanford Site to prepare an integrated assessment of the condition of groundwater.

3. Assess the potential for contaminants to migrate off the Hanford Site through the groundwater pathway.

4. Characterize the groundwater flow system as needed to support other program objectives.

Of the more than 1000 wells on the Hanford Site suitable for groundwater monitoring, approximately 600 are sampled as part of the Groundwater Surveillance Project. To assist in the

(a) Pacific Northwest Laboratory is operated for the U.S. Department of Energy by Battelle Memorial Institute. 
selection of wells and to satisfy the monitoring objectives, nine requirements of the monitoring program have been identified. Wells must be sampled (Bryce et al. 1991)

- in contaminant source areas

- in and bordering known contaminant plumes

- to screen for potential contaminants

- at the Hanford Site perimeter

- near water supplies

- in the confined aquifer

- in offsite locations

- in background or reference areas

- in concert with the Washington State Department of Health.

Recognizing that a more quantitative approach to network design may be applicable, this report explores the development of a quantitative network design method for the Groundwater Surveillance Project at the Hanford Site. Quantitative design methods apply techniques such as simulation, optimization, and uncertainty analysis to the network design process. The method developed in this report uses each of these techniques to some extent. The method primarily addresses objectives 1 and 2 and is most likely to be used to fulfill the first four sampling requirements listed above. This report represents an initial effort to determine the applicability and usefulness of quantitative network design methods in the Groundwater Surveillance Project. 


\subsection{DEVELOPMENT OF A NETWORK DESIGN METHOD}

The approach adopted for developing a method to facilitate the design of Groundwater Surveillance Project monitoring networks is commonly called systems analysis. The systems analysis approach has been applied in many disparate fields where there is a need to manage resources in a complex environment. The approach provides the information required to make appropriate (optimal) decisions in this environment.

A problem requires several attributes for systems analysis to be applied. Haith (1982) summarized these attributes as

1. clearly defined, quantifiable objectives

2. describable by a reasonably tractable mathematical model

3. sufficient data to characterize the effects of altemative solutions

4. no obvious best alternative.

Among these, attribute 4 is perhaps the only one that clearly describes the monitoring network design problem for groundwater surveillance. In the development of the method described below, the remainder of these attributes will be shown to apply in a limited manner to the network design problem. The approach described here follows the general outline presented by Haith (1982).

\subsection{DEFINITION OF THE SYSTEM AND OBJECTIVES}

A general statement of the surveillance network design problem is to specify sampling locations and frequencies for all appropriate water quality parameters such that the four objectives of Section 1.0 are satisfied. This broad definition will be narrowed by defining a system boundary. Only those components and processes of the system that lie within the boundary concern us. In the present application, the system boundary will be defined as that area of the Hanford Site currently or potentially impacted by tritium contamination. A map of the Hanford Site showing the operation areas and the distribution of tritium based on data from 1990 and 1989 is shown in Figure 1. Although tritium is present throughout the Site, the primary sources are located in and near the 200-West and 200-East Areas. The limitation of the system to a single constituent, tritium, constitutes the first major assumption of this analysis. This assumption was made to simplify the analysis. The more realistic case of multiple constituents remains a subject of future investigation.

The four objectives, as stated in Section 1.0, are well defined in a qualitative sense, but are not sufficiently quantitative for the current analysis. For instance, it is not clear what constitutes a 


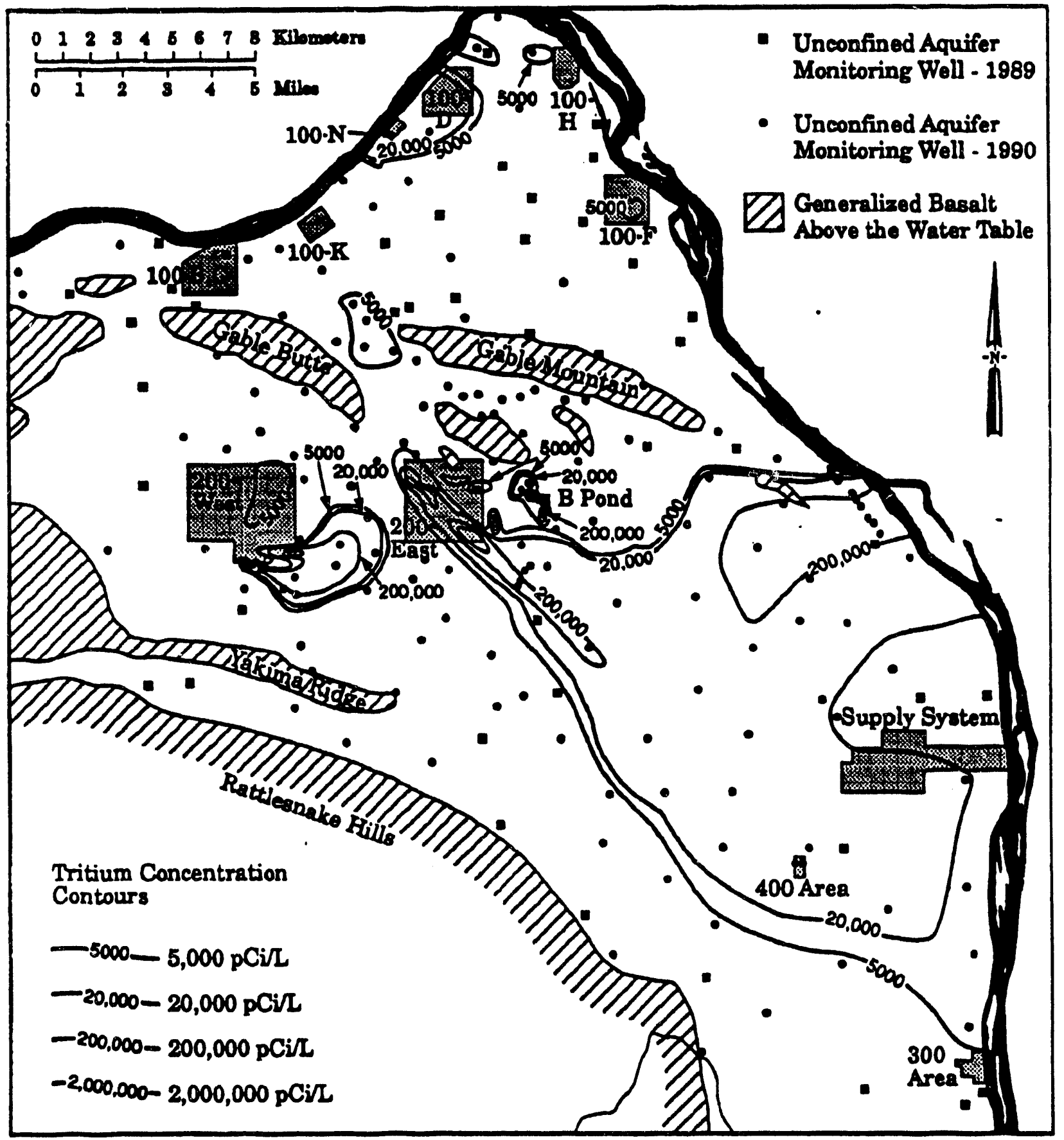

Figure 1. Hanford Site Map and Tritium Distribution Based on 1990 and 1989 Data (from Evans et al. 1992) 
"groundwater quality problem" or how to quantitatively measure either the "condition of groundwater" or the "potential for contaminants to migrate." Well-defined monitoring objectives must come from the decision makers, those parties responsible for choosing the sampling locations and frequencies. Groundwater surveillance at the Hanford Site is somewhat complicated because decisions regarding sampling location and frequency must be made without complete knowledge of how the data will be used. In the design of the network, attempts are made to anticipate questions that might be asked by project participants, DOE, regulatory agencies, and the public, so that the acquired groundwater quality data can support the answers. In this environment, it is difficult to define appropriate quantifiable objectives, a requirement of the current analysis. The remainder of this section describes several quantifiable objectives that may be appropriate for groundwater surveillance monitoring at the Hanford Site.

\subsubsection{Quantifiable Objectives for Groundwater Surveillance}

In most resource allocation problems, cost is an issue and minimizing cost is an objective. For a single constituent, tritium, the total yearly costs associated with groundwater surveillance monitoring can be expressed as a sum of sampling and analysis costs.

$$
C^{\text {tot }}=\sum_{i=1}^{n w}\left(n_{i}^{s} C_{i}^{s}+n_{i}^{a} C^{a}\right) e_{i}
$$

where $C^{\text {tot }}=$ total monitoring costs for the current year

$\mathrm{nw}=$ number of wells available for sampling in the current year

$n_{i}^{s}=$ number of samples taken from well $i$ during each sampling event

$C_{i}^{s}=$ cost of obtaining one sample from well $i$

$\mathrm{n}_{\mathrm{i}}^{\mathrm{a}}=$ number of samples sent to the lab from well $\mathrm{i}$ during each sampling event

$\mathrm{C}^{\mathrm{a}}=$ cost of analyzing one lab sample

$e_{i}=$ number of sampling events at well $i$ in the current year.

Several assumptions are made in the formulation of Equation 1:

1. the same number of samples is taken during each sampling event at well $i$

2. each sample taken from well $i$ has the same unit cost

3. the unit cost of analyzing a lab sample is the same for each sample

4. the same number of samples will be sent to the lab from each sampling event at well $i$

5. sampling locations are restricted to existing wells. 
This last assumption is consistent with past practice of the Groundwater Surveillance Project and with the high costs of well drilling and construction at the Hanford Site. If, however, the construction of additional wells was a consideration, a capital cost term could be added to Equation 1 . The new expression for monitoring costs could be written

$$
C^{\text {tot }}=\sum_{i=1}^{n w^{\prime}}\left(n_{i}^{s} C_{i}^{s}+n_{i}^{a} C^{a}\right) e_{i}+x_{i} C_{i}^{c}
$$

where $n \mathbf{w}^{\prime}=$ number of existing and potential wells available for sampling

$x_{i}=1$ if a new well is installed at location $i, 0$ otherwise

$C_{i}^{c}=$ capital cost of installing a well at location $i$.

Note, the formulation of Equation 2 assumes that $x_{i}=0$ if a well already exists at location $i$.

While minimizing costs is clearly a groundwater surveillance monitoring objective, there are additional conflicting objectives that apply. In the broadest sense, the additional objectives address the issue of information; identification of groundwater problems and assessment of the condition of groundwater require water quality information. Presumably, the more information there is and the higher the quality of that information the better the problem identification and groundwater assessments will be. In the broadest terms, an objective may thus be stated as the maximization of information.

As an operable objective, the maximization of information is no better than the four objective statements of Section 1.0. (In certain ways, it is worse.) By appropriately defining "information," however, useful objectives can be written. Several ways in which information can be defined are listed here.

\section{Definitions of Information}

1. Information is the rate at which the contamination concentration is changing with respect to time. This definition reflects the idea that it is more important to sample wells at which the contaminant concentration is changing rapidly than wells at which the concentration is changing slowly.

2. Information is the inverse of the magnitude of the random fluctuations in contaminant concentration. This definition recognizes that the concentration measured at a well will tend to deviate in a random manner from the actual value. It may be more important to sample wells at which the random fluctuations in concentration are large than those wells at which the concentration is relatively certain. By doing so, the overall uncertainty in the contaminant location is reduced. 
3. Information is the spatial definition or "coverage" of the contaminant plume. This definition recognizes the desire to accurately determine the extent and magnitude of contamination. This measure of information has been explored in several studies as a means of determining the spatial locations of monitoring wells (Loaiciga et al. 1992; Andricevic 1990, 1993, for example). Some measure of the contaminant concentration variance based on spatial statistics has typically been used as a surrogate for information.

Assuming that the rate at which the contaminant concentration is changing with respect to time is known at every potential monitoring location, an objective using definition 1 for the measure of information can be formulated as follows:

$$
\operatorname{maximize} \sum_{i=1}^{n w} d c_{i} e_{i}
$$

where $d c_{i}=M \times a b s\left(\frac{\partial c}{\partial t}\right)$ evaluated at well $i$

$$
\begin{aligned}
M & \left\{\begin{aligned}
& 1 \text { if } \frac{d c}{\partial t}>0 \\
& =1 \text { if } \frac{\partial c}{\partial t} \leq 0
\end{aligned}\right. \\
\text { abs } & =\text { absolute value function } \\
c & =\text { contaminant (tritium) concentration } \\
t & =\text { time. }
\end{aligned}
$$

This objective simply selects for sampling those well locations at which the contaminant concentration is changing most rapidly. Positive concentration changes are weighted by a factor of $M$ over negative concentration changes. When $M>1$, preference is given to sampling wells where the concentration is increasing. A value of $M=1$ results in equal preference being given to positive and negative changes. Under certain circumstances, sampling wells at which the concentration is decreasing may be preferred. The definition of $\mathrm{dc}_{\mathrm{i}}$ could easily be changed to accommodate this condition.

An objective similar in form to Equation 3 can be written using definition 2 for information. This objective assumes that it is possible to measure the random fluctuations in contaminant concentrations at every possible sampling location. This measure represents the uncertainty in knowledge of the concentration. The following objective function selects those wells for sampling at which the uncertainty is highest: 


$$
\operatorname{maximize} \sum_{i=1}^{n w} \frac{u_{i}}{c_{i}} e_{i}
$$

where $\quad u_{i}=$ uncertainty measure such as the standard deviation of contaminant concentration measurements at well $i$

$c_{i}=$ estimate of the (average) contaminant concentration at well $i$.

The uncertainty measure is normalized by $c_{i}$. This reflects the belief that the relative magnitude of contaminant concentration fluctuations with respect to the average concentration is the greater concern, not the absolute magnitude of the fluctuations.

In the actual optimization model, to be presented in Section 2.2, the coefficients of Equations 3 and 4 were scaled to fall between the values of zero and one.

$$
\begin{gathered}
\delta_{i}=\frac{d c_{i}-d c^{\min }}{d c^{\max }-d c^{\min }} \quad d c^{\min } \leq d c_{i} \leq d c^{\max } \\
\delta_{i}=0 \quad d c_{i}<d c^{\min } \\
\delta_{i}=1 \quad d c_{i}>d c^{\max } \\
v_{i}=\frac{\left(u_{i} / c_{i}\right)-(u / c)^{\min }}{(u / c)^{\max }-(u / c)^{\min }} \quad(u / c)^{\min } \leq u_{i} / c_{i} \leq(u / c)^{\max } \\
v_{i}=0 \quad u_{i} / c_{i}<(u / c)^{\min } \\
v_{i}=1 \quad u_{i} / c_{i}>(u / c)^{\max }
\end{gathered}
$$

where the superscripts 'min' and 'max' refer to an appropriate measure of the minimum and maximum coefficient values. In the application presented in Section 3.0, the minimum and maximum coefficient alues were set at the mean value plus or minus two standard deviations. Note, the two coefficients are independently scaled.

Equations 3 and 4 do not incorporate any notion of spatial coverage. They will locate as many samples as possible where the concentration is either changing most rapidly or is the most uncertain. This could result in networks that cluster many samples in the same area. Estimating the extent and configuration of contaminant plumes, however, requires that samples be taken throughout the contaminated area. Most of the techniques presented to provide spatial coverage are based on estimates of the spatial statistics of the concentration (Loaiciga et al. 1992). Sam- 
pling locations can be chosen to minimize the variance of the concentration over the region of interest. Because each sample reduces the variance not only at the sampling location but also in the surrounding area, the monitoring network that minimizes the variance will distribute the sampling points throughout the region of interest. In this study, no attempt was made to estimate the spatial statistics of tritium contamination at the Hanford Site. Spatial coverage of sample location is not implemented as an objective but as a set of constraints. These constraints are discussed in Section 2.2.1.

\subsection{GENERATION AND EVALUATION OF NETWORK ALTERNATIVES}

In the preceding section, quantitative objectives for groundwater surveillance monitoring were presented. These objectives can be used to evaluate the desirability of particular monitoring networks. As part of a complete model, however, they can be used to generate optimal network alternatives. This section presents such a model.

\subsubsection{Construction of the Optimization Model}

The three objectives derived in Section 2.1.1 are

1. Minimize total monitoring costs

2. Maximize information as measured by the change in concentration with respect to time

3. Maximize information as measured by the magnitude of the concentration fluctuations.

One of the strategies for addressing a multi-objective problem is to combine the objectives into a single objective. To do this, the objectives must be written in commensurate units (dollars, for instance). The single objective problem can then be solved for the unique optimal solution. One of the problems with this approach is that in combining multiple objectives with noncommensurate units, a judgement must be made regarding the decision maker's preferences. (The term 'preferences' refers to the amount of one objective a decision maker is willing to give up to improve another objective.) Making such value judgements for the decision maker(s) is generally inappropriate in the development of a model.

One alternative to combining all the objectives into a single objective is to extract the decision maker's preferences and use these to resolve the multi-objective problem. This strategy also produces a single best solution but does not require assumptions about the decision maker's pref- 
erences. Unfortunately, it is inherently difficult to obtain accurate and consistent estimates of a subjective quantity such as preferences [see Cohon (1978) for a discussion].

The method of multi-objective analysis adopted here is to generate a set of alternatives that are noninferior to each other and superior to all other feasible alternatives. Two solutions are noninferior to each other if their order of preference cannot be determined bascd solely on their objective function values. The noninferior set of alternatives is generated by building an optimization model with a single objective, monitoring costs in our case, and writing the other objectives as constraints. A proto-model for the groundwater surveillance monitoring network design problem is given here.

$$
\begin{array}{ll}
\underset{\text { minimize }}{\text { tot }}= & \sum_{\substack{i=1 \\
\text { subject to }}}^{n w}\left(n_{i}^{s} C_{i}^{s}+n_{i}^{a} C^{a}\right) e_{i}=\sum_{i=1}^{n w} C_{i} e_{i} \\
& \sum_{\substack{i=1 \\
n w}}^{n w} \delta_{i} e_{i} \geq \alpha \\
& \sum_{i=1} v_{i} e_{i} \geq \beta
\end{array}
$$

The proto-model minimizes the total monitoring costs subject to constraints on the values of the information objectives. The constraints require that the information objectives be greater than the constants $\alpha$ and $\beta$. For a given value of $\alpha$ and $\beta$, solving the optimization model will provide a single optimal network, a member of the noninferior set. By solving the model repeatedly for various values of $\alpha$ and $\beta$, the entire noninferior set can be generated. When $\alpha$ is large and $\beta$ is small, the network will emphasize monitoring in those regions where the contaminant concentration is changing most rapidly. When $\alpha$ is small and $\beta$ is large, the network will emphasize monitoring in those regions where the concentration uncertainty is the highest. Larger values of either constant will require more samples and thus a larger cost.

The coefficients in the cost objective (Equation 7) are expressed as a single coefficient, $C_{i}$, which is the total cost of a single sample from well $i$. Groundwater monitoring costs for the surveillance project at the Hanford Site are typically not differentiated according to location. In this case, the cost coefficients, $C_{i}$, can be set equal to unity for all well locations. The optimization model will then simply minimize the total number of samples subject to the information constraints. 
A spatial constraint on sampling is added by dividing the system domain (the Hanford Site in this case) into a set of subdomains and requiring that a specific number of samples be taken from each subdomain. The constraint is written as follows.

$$
\sum_{i \in N_{k}} e_{i} \geq \gamma \quad k=1,2, \ldots, N S D
$$

where $\mathbf{N}_{\mathbf{k}}=$ set of all potential sampling locations in subdomain $\mathbf{k}$

$$
\gamma=\text { minimum number of samples required in each subdomain }
$$

NSD = number of subdomains.

Note, any given well may be in more than one subdomain and a sample at such a well will satisfy the constraint for each subdomain in which it is located. Setting $\gamma=0$ results in a model that has no spatial sampling requirements.

Constraints are also added to the model specifying the minimum and maximum number of samples at each well. In addition, the model includes constraints that specify an integer solution. The complete model is given here.

$$
\begin{aligned}
& \text { minimize } \quad C^{\text {tot }}=\sum_{i=1}^{n w} C_{i} e_{i} \\
& \text { subject to } \quad \sum_{i=1}^{n w} \delta_{i} e_{i} \geq \alpha \\
& \sum_{i=1}^{n w} v_{i} e_{i} \geq \beta \\
& \sum_{i \in e_{i}} \geq \gamma \quad k=1,2, \ldots, N S D \\
& e_{i}=\left\{\begin{array}{lcl}
e_{i 0}+2 e_{i 1}+4 e_{i 2} & \forall i & \text { if MINS =1 } \\
2 e_{i 0}+3 e_{i 1}+4 e_{i 2} & \forall i & \text { if MINS = 2 } \\
3 e_{i 0}+4 e_{i 1} & \forall i & \text { if MINS =3 } \\
4 e_{i 0} & \forall i & \text { if MINS =4 }
\end{array}\right. \\
& e_{i} \leq \mathrm{MAXS} \\
& e_{i j} \in\{0,1\} \quad \forall i ; j=0,1
\end{aligned}
$$

where MINS = minimum number of sampling events during the year at any well that is sampled at least once 
MAXS = maximum number of sampling events during the year at any well

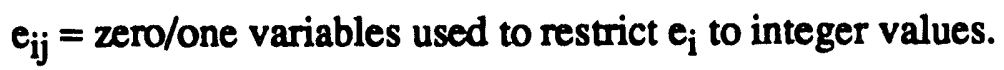

All other symbols have been previously defined.

Equation 15 serves two functions. It forces the value of $e_{i}$ to be an integer value and to be greater than or equal to MINS. In the construction of the optimization model, only one of the equalities given as Equation 15 is used depending on the value of MINS. Note that the constants MINS and MAXS are not independent. The value of MAXS should obviously be at least as large as MINS. In addition, if MAXS is greater than four, Equation 15 may need to be altered, depending on the actual values of MAXS and MINS.

\subsubsection{Determination of the Objective Function Coefficients}

The crucial components of the optimization model presented above are the coefficients of the explicit objective function and the coefficients of the two implicit objectives (Equations 12 and 13). The values of these coefficients will determine the locations and the sampling frequencies of the noninferior monitoring networks. Because the mechanism for funding groundwater surveillance monitoring at the Hanford Site does not consider the variation in monitoring costs with well location, the cost coefficients, $C_{i}$, were all set equal to unity. As stated previously, the model objective thus minimizes the total number of sampling events for the year.

The coefficients $d c_{i}$ and $u_{i}$ (Equations 3 and 4) are measures of the rate of change with respect to time and the uncertainty, respectively, of the tritium concentration. Two possibilities for specifying values of these coefficients were considered. The first possibility was to develop a physically based (numerical) model of the Hanford Site that could accurately reproduce the measured tritium distribution. This transport model could be used to predict the change in tritium concentration over the design year at every potential sampling location. This prediction would serve as the coefficient $\mathrm{dc}_{\mathrm{i}}$. The uncertainty measure, $\mathrm{u}_{\mathrm{i}}$, could be estimated by comparing, over some period of record, the difference between the observed tritium concentration and the transport model output.

The physically based model approach is attractive because the predictions of the transport model would be based on known physical transport processes and could be conditioned on all available data, such as groundwater head and tritium concentration measurements. Unfortunately, a model of the Hanford Site capable of making accurate predictions of tritium transport in three 
dimensions does not currently exist. An alternative means of estimating $d c_{i}$ and $u_{i}$ was thus devised.

One of the unusual characteristics of the network design problem for the Hanford Site is the availability of large amounts of historical groundwater monitoring data. Many of the wells on the Site have been sampled for tritium since the early 1960 s. This extensive historical database was used in a purely statistical analysis to estimate the network design model coefficients. The weakness of this approach is that it uses only the available tritium concentration measurements and does not consider physical processes of groundwater flow and solute transport.

The approach adopted for estimation of the network design model coefficients was time series analysis (Box and Jenkins 1976; Harvey 1981). A time series is a sequence of measurements of some property, in this case the tritium concentration at each well. Time series analysis attempts to fit a simple statistical model to the concentration measurements. This model can then be used to forecast future values of the concentration and to estimate the uncertainty in these forecasts. The coefficients of the optimization model are calculated directly from the forecast and the uncertainty.

Figure 2 illustrates the procedure used to calculate the model coefficients. The measured values represent a time series of tritium concentration at well 699-1-18 on the Hanford Site from 1980 through the first half of 1992 . Although many wells have tritium measurements going back to the early 1960 s, only data acquired since 1980 was used in this analysis. Using all of the concentration data would result, in some cases, in poorer estimates of the trend and the uncertainty because of large fluctuations in measured concentration during earlier site operations. Standard time series analysis requires that the data be spaced at regular intervals. While the majority of the measurements from the Hanford Site wells were taken at relatively uniform intervals, there are many instances in which the interval between samples varies significantly, as can be seen in Figure 2. In particular, the absence of measurements during 1990 and 1991 reflects the change in the analytical laboratory contract and is typical of the current state of the Hanford Site database.

Each measured time series was processed to produce an approximation to the measured series but with equal intervals (see Figure 2). The frequency, F, of the approximate series was based on the median interval in the measured data series. The frequency was rounded to the nearest integer value. For well 699-1-18, the frequency of the approximate series was found to be four samples per year. Each year between 1980 and 1992 was then divided into F equal intervals. Each of these intervals was assigned a concentration value equal to the arithmetic average of all mea- 


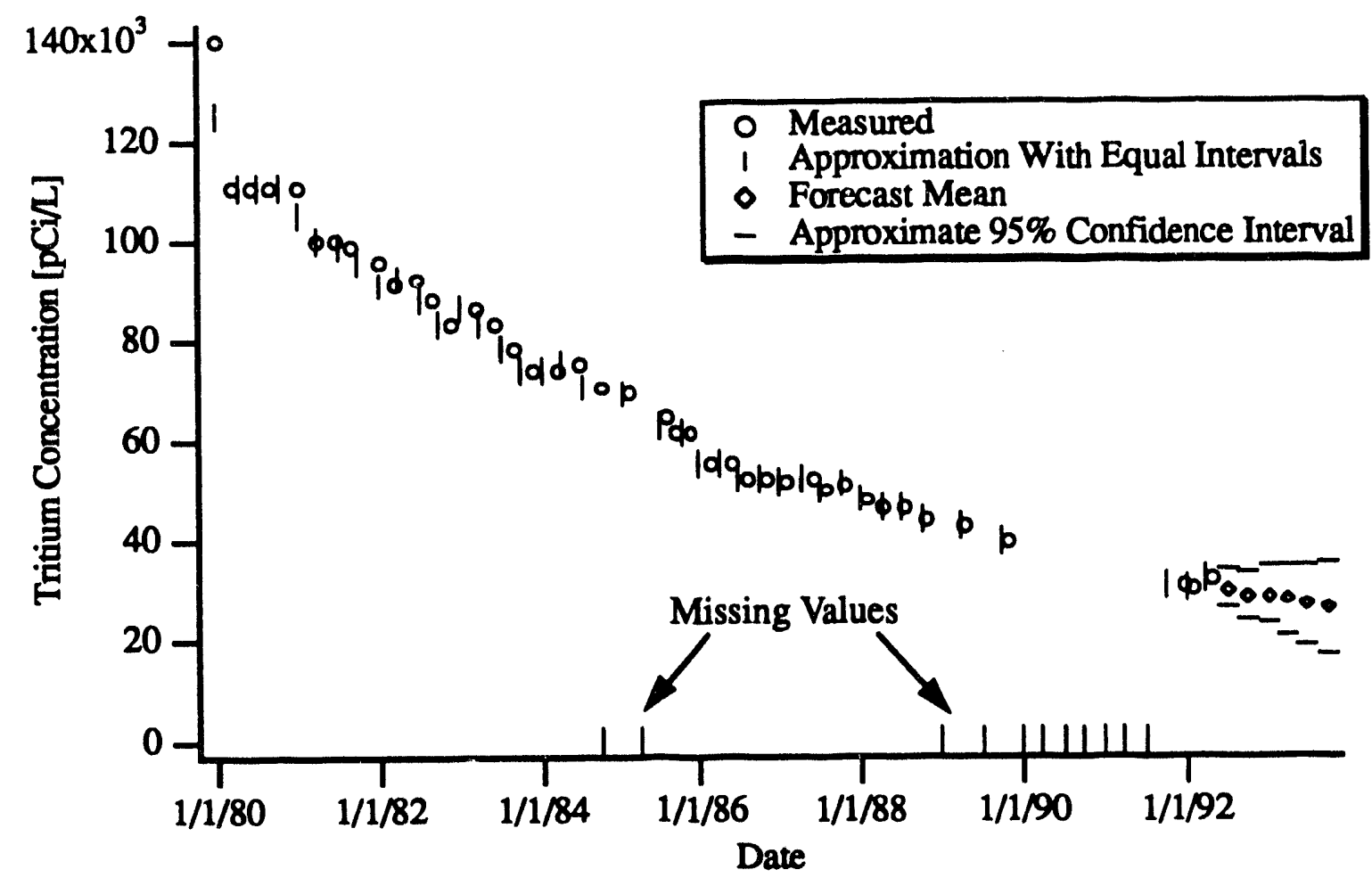

Figure 2. Measured Time Series for Well 699-1-18 and Its Equal Interval Approximation. Forecasted values for 1993 are also shown along with approximate 95\% confidence intervals.

sured concentration values falling within that interval. If an interval contained no data measurements, however, the value of that interval was set to a non-numeric value. These points are plotted in Figure 2 with a value of zero. The time series analysis software was able to account for these non-numeric values signifying a lack of a measurement. The first measured data point after January 1,1980 , defined the beginning of each approximate series. If the second, third, or fourth intervals contained no measured data points, a value was assigned based on a linear trend from the initial data value to the first numeric value falling in the fifth or higher interval. This was done to satisfy a requirement of the analysis software.

Once the approximate time series was defined, the statistical software S-PLUS was used to model the series and forecast values through the end of 1993. Time series analysis will not be discussed here; a description can be found in Box and Jenkins (1976) or Harvey (1981). Details of the implementation in S-PLUS can be found in the S-PLUS User's Manual (Statistical Sciences, 
Inc. 1991). Box and Jenkins (1976) suggested a three-step iterative procedure for time series modeling.

- Determine the number of model parameters.

- Estimate the parameter values.

- Attempt to validate the model.

Presumably, each well on the Hanford Site could best be represented by a unique time series model. Because of the large number of wells on the Hanford Site, however, this iterative procedure could not be effectively carried out for each well. An automated analysis was required. The three-step procedure was carried out for a small subset of wells to determine the most effective number of model parameters to use for all of the wells. Each well would thus be modeled using the same number of parameters. The only difference between wells would be the values of the parameters.

The basic model used in time series analysis is the autoregressive moving average (ARMA) model (Box and Jenkins 1976; Harvey 1981). An ARMA(p,q) process, $x_{t}$, can be written as

$$
x_{t}-\phi_{1} x_{t-1}-\ldots-\phi_{p} x_{t-p}=\varepsilon_{t}-\theta_{1} \varepsilon_{t-1}-\ldots-\theta_{q} \varepsilon_{t-q}
$$

where $\phi$ and $\theta$ are the autoregressive and moving average parameters, respectively. The innovations process, $\varepsilon$, is a white noise process. This ARMA model is appropriate for stationary, zeromean time series.

The concentration at many wells is neither stationary nor zero-mean (e.g., Figure 2). The model in Equation 18 can still be used, however, by differencing the concentration series. If the parameter, $d$, is defined as the level of differencing, then the differenced series is defined as follows:

where $\quad c_{t}=$ concentration time series

$$
\begin{array}{ll}
x_{t}=c_{t}-c_{t-1} & \text { for } d=1 \\
x_{t}=c_{t}-2 c_{t-1}+c_{t-2} & \text { for } d=2
\end{array}
$$

$$
\mathbf{x}_{\mathbf{l}}=\text { differenced series. }
$$

Applying a d-level differenced series to an $\operatorname{ARMA}(p, q)$ model results in an autoregressive-integrated moving average, ARIMA(p,d,q) model (Box and Jenkins 1976). Based on an examination of a number of concentration series from Hanford Site wells, it was determined that an appropriate model to use for the majority of wells was an $\operatorname{ARIMA}(2,2,1)$ model. 
The parameters of the $\operatorname{ARIMA}(2,2,1)$ model, $\phi_{1}, \phi_{2}$, and $\theta_{1}$, were estimated for each well using a maximum likelihood method (see Statistical Sciences, Inc. 1991; see also Kohn and Ansley 1986; Bell and Hillmer 1987; and Jones 1980). After estimating the parameters, the model was used to forecast the mean concentration through 1993 (see Figure 2). The average rate of change of the mean forecasted concentration during 1993 was then calculated. This value was used as the coefficient $\mathrm{dc}_{\mathrm{i}}$ (Equation 3). Along with the forecasted mean value, S-PLUS calculated an approximate forecast error. Figure 2 shows approximate $95 \%$ confidence intervals based on this error. The average for 1993 of the forecast error divided by the forecast mean was taken as the coefficient $\left(u_{\mathfrak{i}} / c_{\mathfrak{i}}\right)$.

Not all wells that have tritium data from 1980 or later were fit with a time series model. Wells were discarded if there were no concentration measurements in the 5 years preceding the year for which forecasted values were required (1993 in this case). These wells were discarded because the reliability of a time series forecast depends strongly on the availability of recent measurements. A time series model was also not fit to those wells at which fewer than six tritium measurements were available. For these wells, a linear least squares model was used. The optimization model coefficients $d c_{i}$ and $u_{i}$ were based on the slope and the standard deviation of the residuals, respectively, of the best fit linear model.

Because the time series model was fit to each well automatically (i.e., without visual interaction to determine the order of the ARIMA model as defined by the parameters, $p, d$, and $q$ ), the best possible fit was not obtained for every well. The time series model nonetheless provides a reasonable forecast of the concentration in almost every case and seems to be a good conipromise between accuracy and practicality.

\subsubsection{Solution of the Optimization Model}

Determining the coefficients $\delta_{\mathrm{i}}$ and $v_{\mathrm{i}}$ is the major difficulty in fully specifying the optimization model. If there are no spatial sampling requirements (i.e., $\gamma=0$ in Equation 14), then the model (Equations 7-17) is completely specified by setting MINS and MAXS, the minimum and maximum number of samples aliowed during a year. (This assumes the cost coefficients, $C_{i}$, are known.) The model at this point can be solved by any integer programming software. In this study, XMP/ZOOM (Marsten 1981) was used. As discussed above, the value of the parameters $\alpha$ and $\beta$ (Equations 12 and 13) was varied, with each parameter combination resulting in a network solution. 
If a spatial requirement (Equation 14) is included in the model, the wells located in each of the spatial subdomains must be specified. As discussed earlier, the process of specifying subdomains is subjective and should be based on prior information about where the contaminant is located.

The optimization model (Equations 7-17) has many solutions that are close to optimal. In the results presented in Section 3.0, the true optimal solution was often never found. The first step of the solution process was to determine a lower bound on the cost objective. The first feasible network solution found that had a cost within $5 \%$ of this bound was subsequently accepted as the optimal solution. The solution process initially used a heuristic method (Marsten 1981), only moving to a more sophisticated and time-consuming method (Branch and Bound) when none of the heuristic solutions came within $5 \%$ of the cost bound. 


\subsection{NETWORK OPTIMIZATION RESULTS}

In this section results are presented for an application of the optimization model to the monitoring of tritium at the Hanford Site. At the time data were extracted (Fall, 1992), there were 340 wells with tritium samples taken between 1980 and the first half of 1992 in the HEIS database. Note that this includes 600 Area wells only. The 600 Area wells monitor the large-scale movement of the tritium plume and as a consequence are most appropriate for this analysis. Of the 340 wells located in the 600 Area, 31 had not been sampled in the last 5 years and were altimately discarded as discussed above. In addition, 29 wells were discarded because they had just one sample in the database since 1980. Time series analysis (linear least squares fit for wells with fewer than six samples) was carried out for the remaining 280 wells with the optimization model coefficients calculated as described in the Section 2.2.2. In addition, the mean value of the forecasted concentrations for 1993 (the mean measured value for those wells with fewer than six samples) was determined.

Of the 280 wells to which a model was fit and optimization model coefficients were calculated, 163 had a mean concentration less than $500 \mathrm{pCi} / \mathrm{L}$, the approximate detection limit for tritium. This gives some indication of the extent of the surveillance monitoring at the Hanford Site. The tritium sampling has clearly been covering much more than the existing tritium plume(s). The 163 wells with a mean concentration less than $500 \mathrm{pCi} / \mathrm{L}$ were not included in the network optimization problem. The total number of wells available to the optimization model was thus 117.

The coefficients $d c_{i}$ and $u_{i} / c_{i}$ of the 117 available wells have a skewed distribution with numerous outliers. This distribution has a detrimental effect on the scaling process (Equations 5 and 6) by compressing the majority of the coefficient values into a very small minge. The coeffcients of the 117 wells were transformed before scaling as follows:

$$
\begin{array}{cr}
d c_{i}=\log \left(5 \times d c_{i}\right) & \text { for } d c_{i}>0 \\
d c_{i}=\log \left(a b s\left(d c_{i}\right)\right) & \text { for } d c_{i}<0 \\
\frac{u_{i}}{c_{i}}=\log \left(\frac{u_{i}}{c_{i}}\right) &
\end{array}
$$

The effect of the log transformation is to produce a more Gaussian distribution of the coefficients. In order to further reduce the effect of the outliers, the minimum and maximum values chosen for the scaling were set to the mean value plus or minus two standard deviations. Note that the coeffi- 
cients obtained with the time series fit were scaled separately from the coefficients obtained with the linear least squares fit.

Positive changes in concentration were emphasized by multiplying the coefficient $\mathrm{dc}_{\mathrm{i}}$ by a factor of five (Equation 20). The effect of this is reduced by the log transformation, however. Note that when $d c_{i}$ is negative, the absolute value is taken. A well in which the concentration is changing, whether in a positive or negative direction, is thus more likely to be sampled than a well in which the concentration is constant.

Problems were solved both with and without a spatial requirement on sample locations. With no spatial requirement (i.e., $\gamma=0$ in Equation 14), the optimization model is free to sample without regard to clustering of samples. As an alternative, the Hanford Site was divided into subdomains covering approximately $4 \mathrm{mi}^{2}\left(10.4 \mathrm{~km}^{2}\right)$. The spatial requirement was that the network solution must have at least two samples from each subdomain in which one or more of the 117 eligible wolls was located. The spatial subdomains are shown in Figure 3. Indicated in each subdomain is $\mathrm{i}$ he number of wells in that subdomain for which $\mathrm{dc}_{\mathrm{i}}, \mathrm{u}_{\mathrm{i}}$, and the mean concentration value $c_{i}$ were calculated (a total of 280 wells). Also indicated is the number of wells in each subdomain for which $c_{i}$ was greater than $500 \mathrm{pCi} / \mathrm{L}$ (a total of 117 wells). Several of the subdomains have no wells located in them; these are left blank.

As illustrated in Figure 3, many of the subdomains contain wells that have been sampled in the last 5 years but have not had a concentration above $500 \mathrm{pCi} / \mathrm{L}$. (These subdomains are labeled \#/0.) As stated previously, no sampling requirement was written for these subdomains. Many of the subdomains contain a single eligible monitoring well (those labeled \#/1). In the network solutions with spatial sampling requirements, these wells must be sampled at least twice per year. The optimization model is allowed to choose, however, whether they should be sampled more frequently. The total number of subdomains in which an eligible well is located is 49 . Any solution to the optimization model with the spatial sampling requirements must thus sample from at least 49 different wells.

The result of solving the optimization model for a range of values of $\alpha$ and $\beta$ with no spatial sampling requirement is shown in Figure 4. Recall that $\alpha$ and $\beta$ are the parameters that determine the level of importance of the two information objectives: the rate of concentration change and the concentration uncertainty, respectively. The figure shows contours of the total number of yearly samples as a function of the parameters $\alpha$ and $\beta$. Each + symbol represents a solution of the optimization model (Equations 7-17), which was solved for $\alpha$ values up to 170 and $\beta$ values to 180 . 


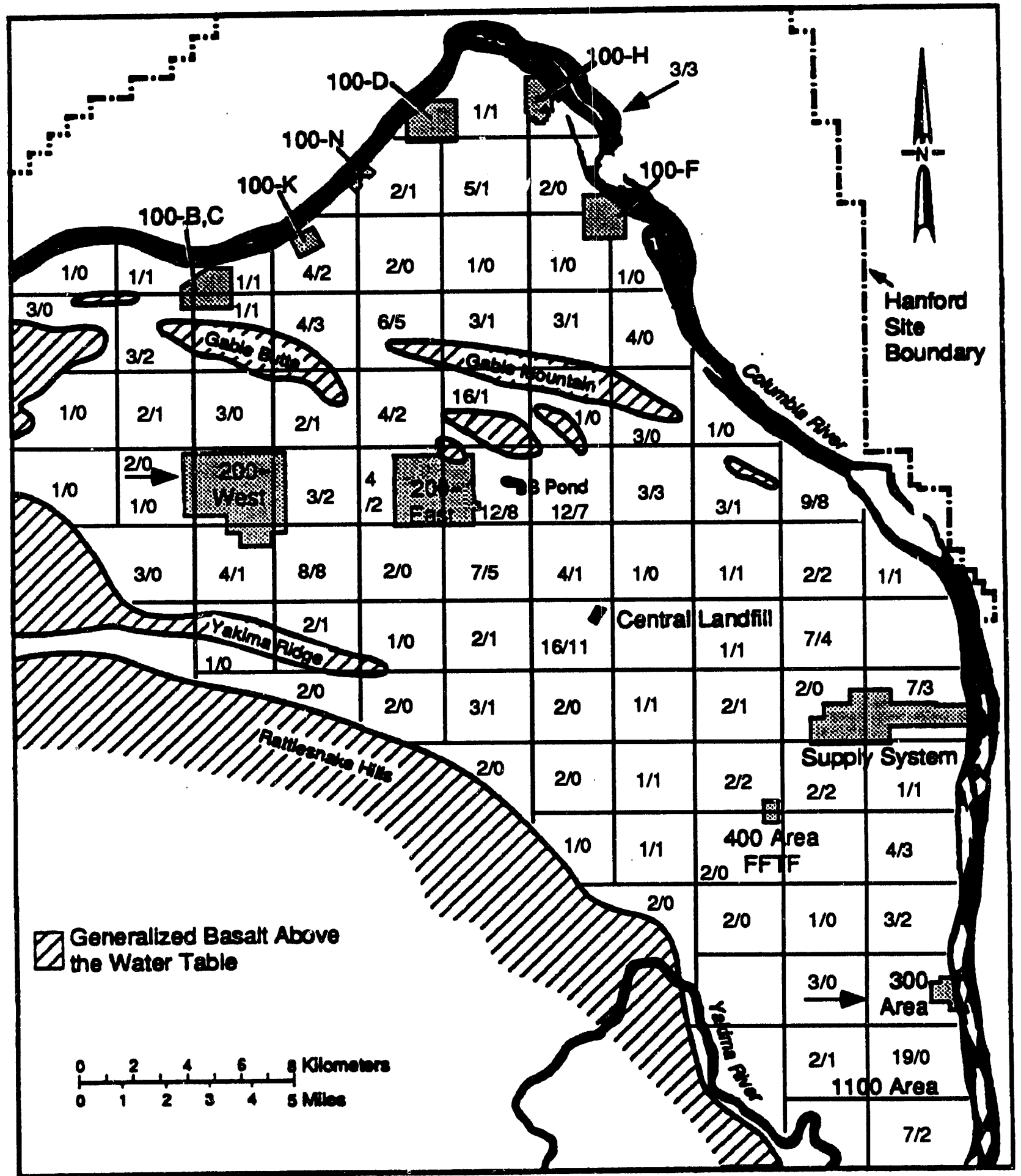

Figure 3. Spatial Subdomains for the Optimization Model. First number in each subdomain indicates the number of wells for which a mean concentration was calculated (total $=280$ ). Second number indicates the number of wells with a mean concentration greater than $500 \mathrm{pC} / \mathrm{L}$ (total $=117)$. 
Although the contours are drawn across the entire plot, they should be interpreted as meaningful only within the region containing model solutions. The interval between contours is 20 samples.

Each of the contours in Figure 4 represents the fewest number of samples that can be taken (the minimum cost solution) and still achieve the required level of the other two objectives, as specified by the $\alpha$ and $\beta$ values. Note that a trade-off exists between the information objectives. For a constant number of samples, one objective cannot be increased without decreasing the other. This trade-off exists because the wells that have a high degree of uncertainty are not, in general,

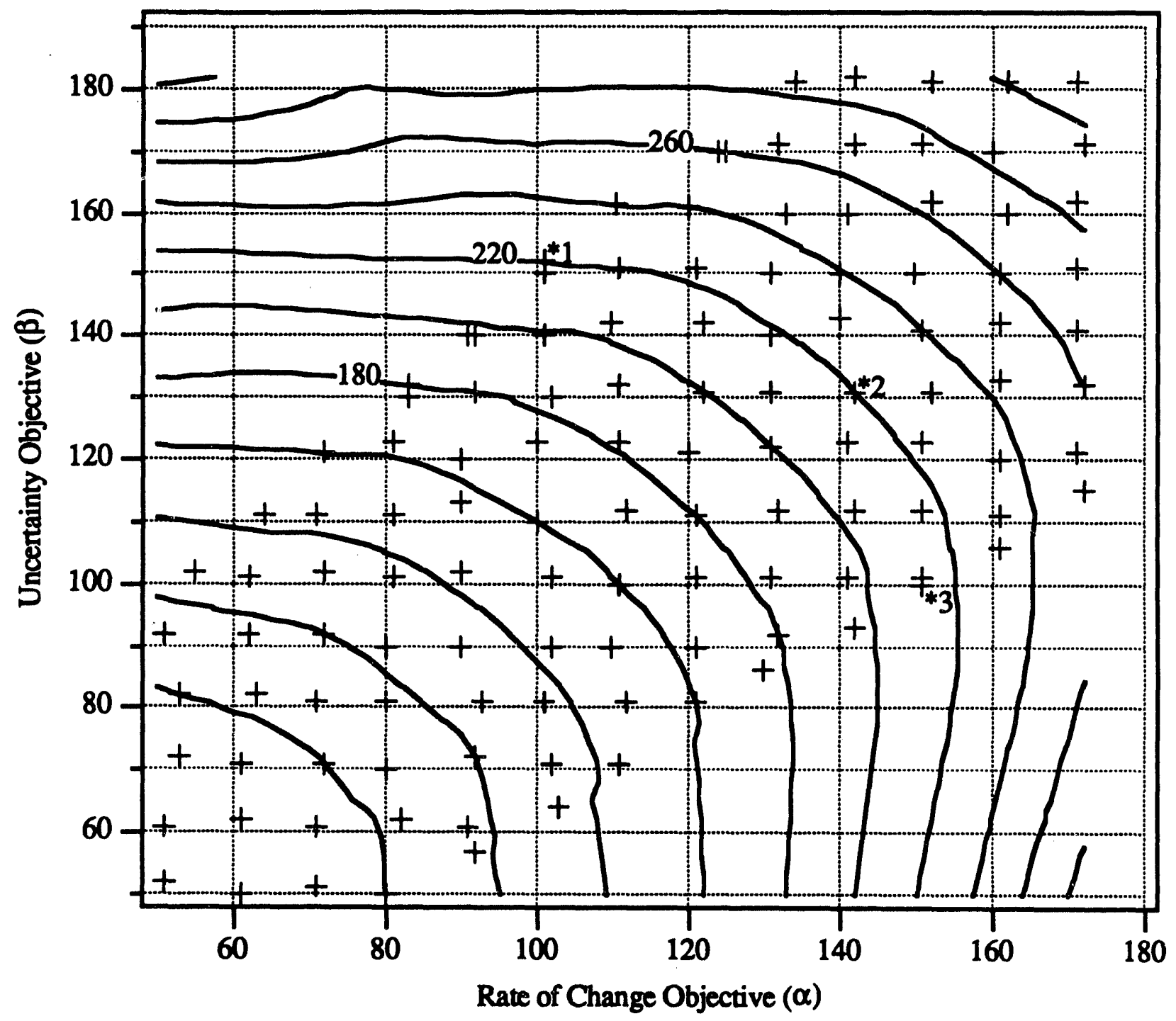

Figure 4. Contours of the Optimal Number of Samples Per Year as a Function of the Information Objectives - No Spatial Sampling Requirements (Asterisks indicate networks discussed in the text.) 
the wells at which the concentration is changing quickly. It can also be observed that the solutions to the optimization model fall in a band about the line $\alpha=\beta$. There is no solution at $\alpha=60$, $\beta=150$ for instance. This is because, for the same number of samples, a solution with $\alpha=100$, $\beta=150$ exists. This latter solution is obviously superior and will be chosen by the optimization model. There is also a trade-off between the cost and each of the information objectives. These trade-offs are approximately linear as evidenced by the nearly equal spacing between cost contours in Figure 4. That is, an additional 20 samples will increase the information objectives by the same amount regardless of the cost. This relationship may not hold for costs (number of samples) greater than 300 .

Because the information objectives have no physically meaningful units, it is difficult to understand the consequences of moving from one network solution to the next along a contour of a constant number of samples. To help illustrate the effect of $\alpha$ and $\beta$ on the optimal networks, three networks of approximately 220 samples per year were compared. The location of these networks in objective function space is indicated in Figure 4 with a small asterisk followed by a number. Notice that the three networks all lie near the 220 sample contour. The networks were chosen to represent differences in the relative importance of the information objectives.

Network 1 represents a network that would be preferred when the uncertainty objective is much more important than the concentration change objective. Network 3 represents the opposite - a network preferred when the uncertainty objective is relatively unimportant. Network 2 is a network that would be preferred when the two objectives have approximately equal weight.

The three optimal networks are presented as Figures 5-7. The sampling frequency for each well is indicated by color. As the figures illustrate, the optimal sampling frequency for nearly every well is the maximum allowed, four samples per year. This result is chiefly because of the lack of spatial constraints. In addition, the solution method of the optimization model tended to produce networks with all wells sampled at the maximum frequency. Figures 5-7 also illustrate a noticeable clustering of wells at several locations (particularly near B Pond and the Central Landfill). This is a consequence of both the form of the optimization model and the lack of a spatial sampling requirement.

Comparing Figures 5 and 6 illustrates the effect of emphasizing one information objective over the other. Emphasizing uncertainty (Figure 5) results in a network that is less clustered and has wells spread over a larger area. In particular, a much larger number of wells are located in the northern part of the site near the 100 Areas. When the rate of change of the tritium concentration 


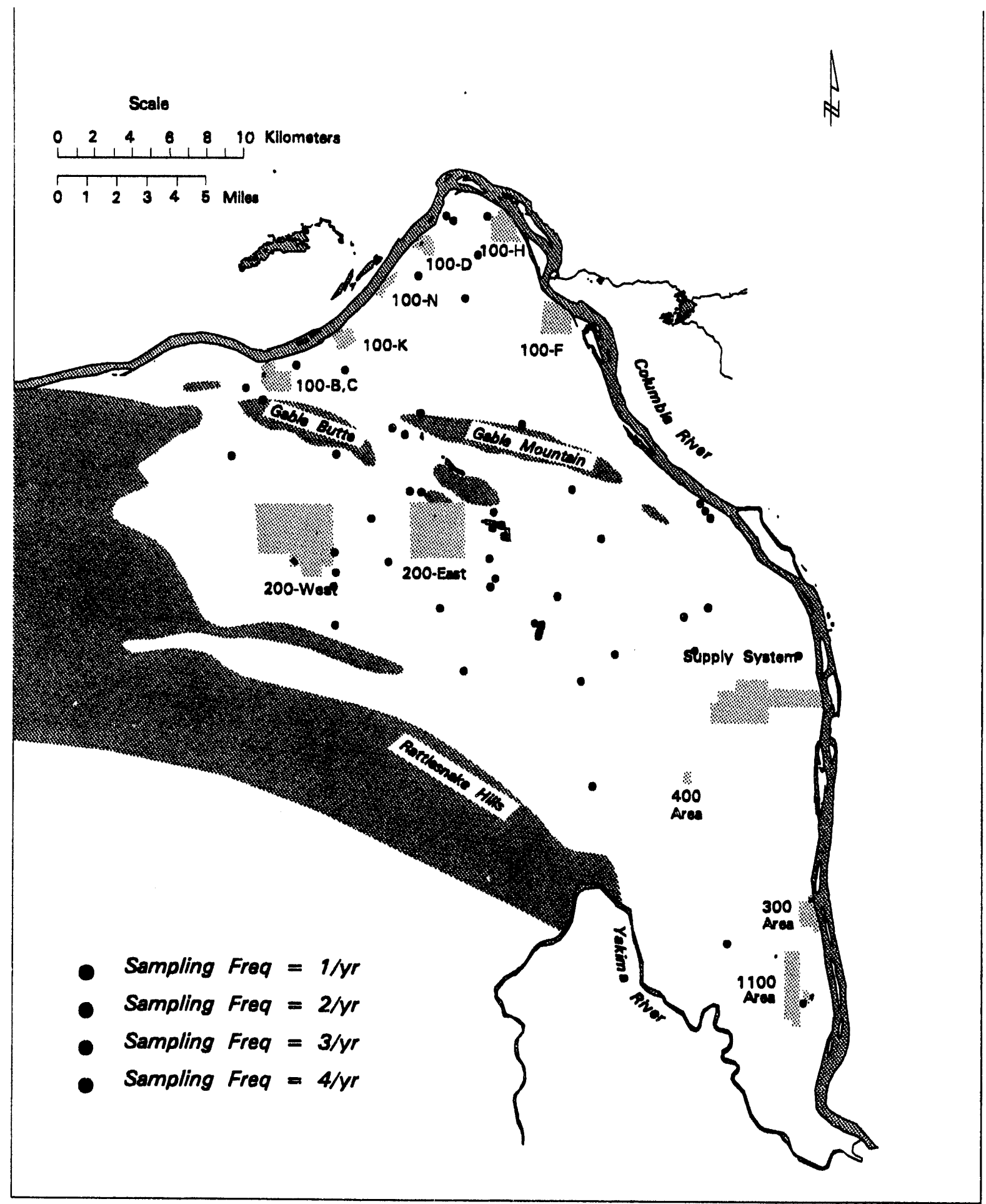

Figure 5. Optimal Network Solution Emphasizing the Uncertainty Objective $(* 1$ in Figure 4) - No Spatial Sampling Requirements. Network consists of 217 samples from 55 locations. 


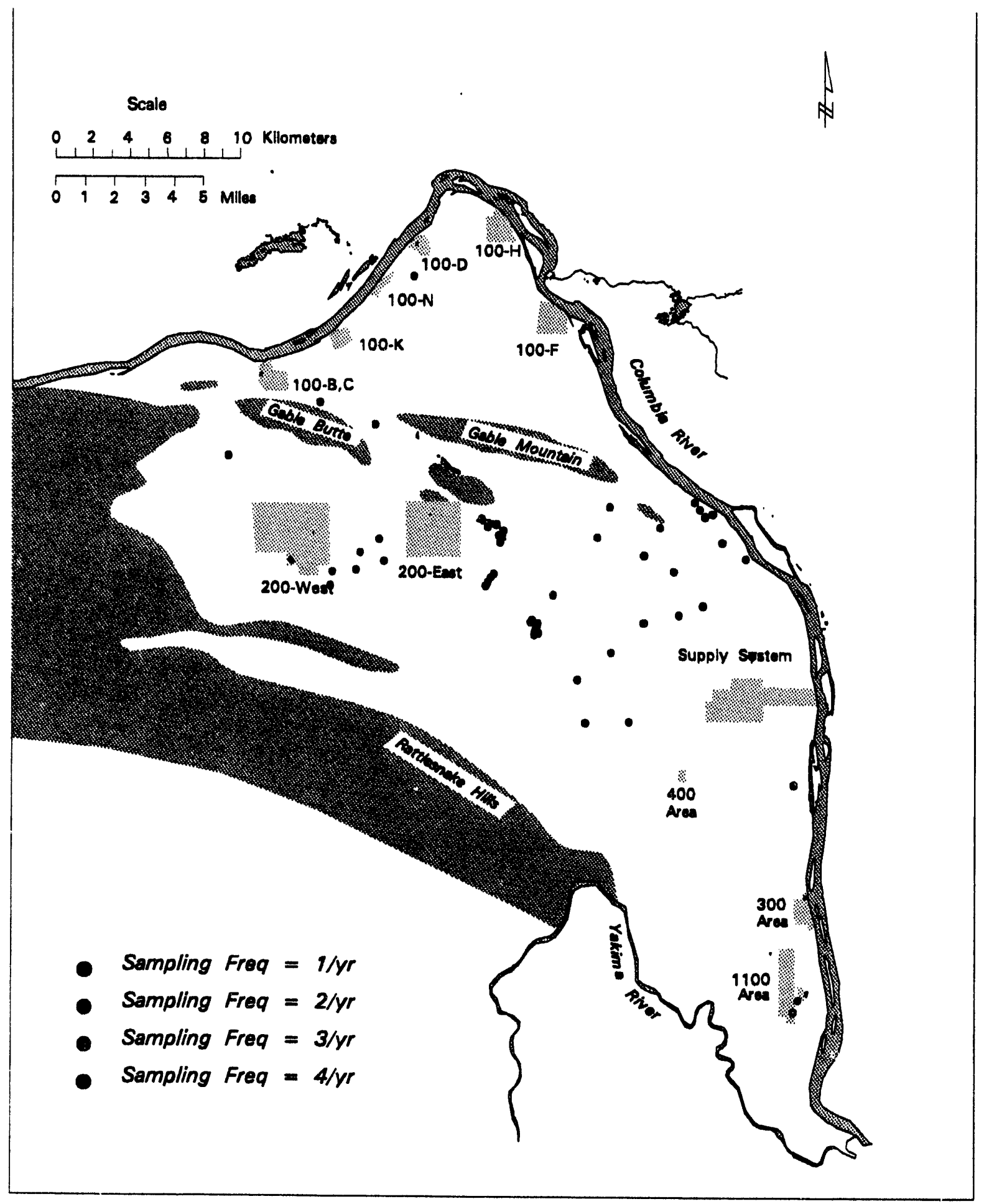

Figure 6. Optimal Network Solution Emphasizing the Concentration Change Objective $(* 3$ in Figure 4) - No Spatial Sampling Requirements. Network consists of 208 samples from 52 locations. 


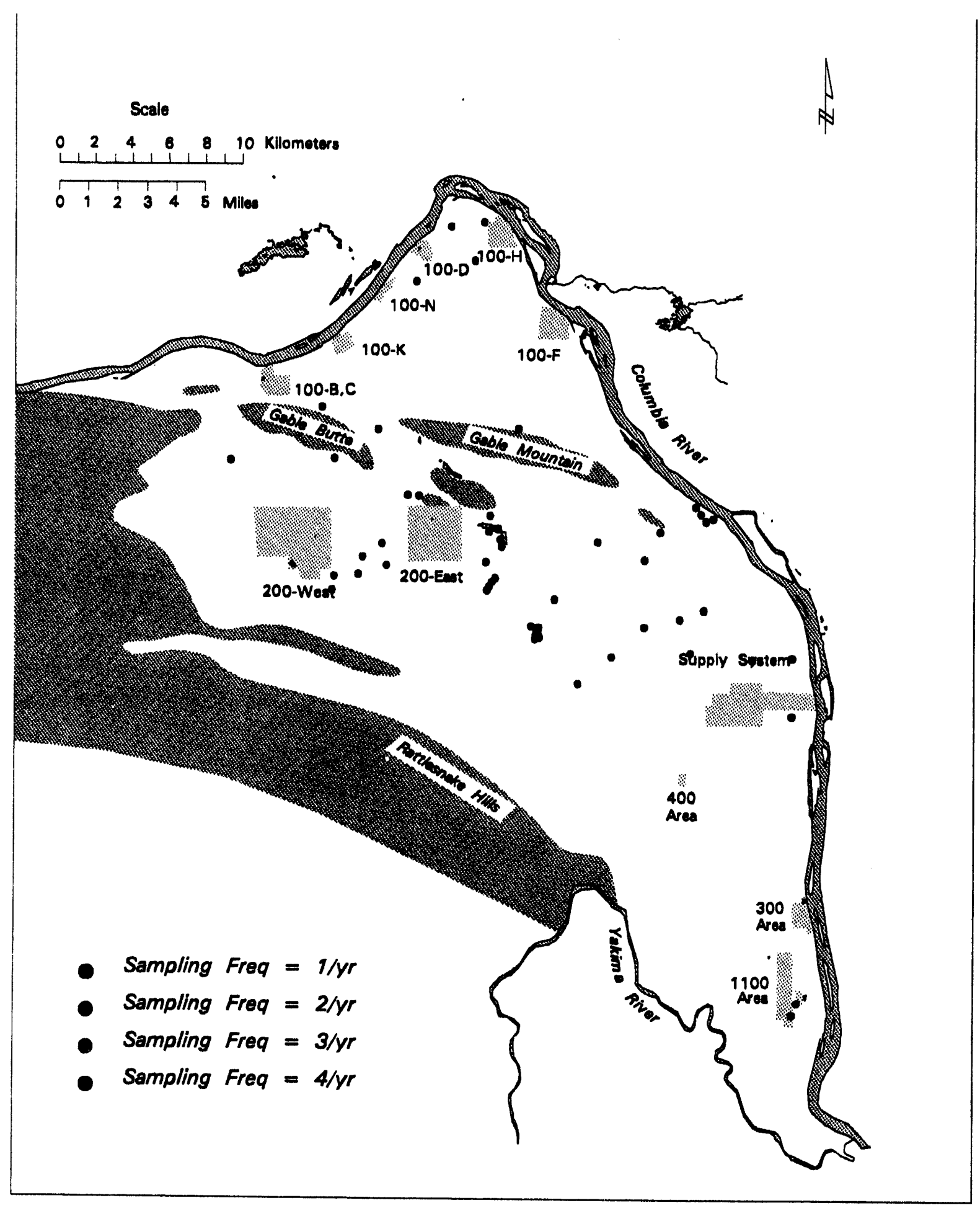

Figure 7. Optimal Network Solution with Equal Emphasis on the Information Objectives (*2 in Figure 4) - No Spatial Sampling Requirements. Network consists of 220 samples from 55 locations. 
is emphasized (Figure 6), the 100 Areas are almost completely ignored and there is pronounced clustering at several locations that can be related to the location of the tritium plume. The network that represents equal emphasis of the two information objectives (Figure 7) shows a balance between the two more extreme networks.

Adding the requirement that the spatial subdomains in which one or more eligible monitoring wells are located be sampled at least twice ( $\gamma=2$ in Equation 14) has a pronounced effect on the network solutions. Contours of the number of samples as a function of the information objectives are shown in Figure 8 for $\gamma=2$. Once again, the contours are only meaningful within the area of the data points. With $\gamma=0$, the optimization model ignores Equation 14 and, for many problems, is able to find solutions for which the information constraints are binding (i.e., Equations 12 and 13 are equalities). With $\gamma=2$, however, the optimization model must allocate samples that are inefficient with respect to the information constraints to satisfy the spatial constraints. This results in many solutions for which one or both of the information constraints are nonbinding. The presence of nonbinding constraints is reflected in Figure 8 by the narrow band within which the network solutions fall. The range of the solutions for $\gamma=0$ is noticeably broader (see Figure 4).

A comparison of Figures 4 and 8 also shows that the spatial sampling constraints result in more costly solutions. The solution that satisfies $\alpha=140, \beta=150$ requires 240 samples when there are no spatial requirements and 260 samples in the presence of the requirements. This is a general characteristic of optimization: the cost of the solutions increases as the problem becomes more constrained.

As in the preceding discussion, there are two network solutions indicated in Figure 8 with asterisks that represent varying emphasis on the two information objectives. These two networks were chosen to have approximately the same total number of samples (220) as Figures 5 through 7. Network 1 places greater emphasis on the uncertainty objective and is shown in Figure 9. The most notable effect of the spatial constraints is that sampling frequencies of two and three samples per year are chosen; compare this to the exclusively four samples per year of Figure 5. In addition, the spatial constraints result in 20 more wells being sampled. The network emphasizing the rate of change in tritium concentration ( $* 2$ in Figure 8 ) is shown in Figure 10. The marked clustering at the center of the Site is similar to Figure 6, but the spatial constraints cause additional wells to be sampled throughout the site.

The difference between the networks of Figures 9 and 10 is qualitatively much less than the difference between the networks of Figures 5 and 6. This is, again, reflective of the additional 


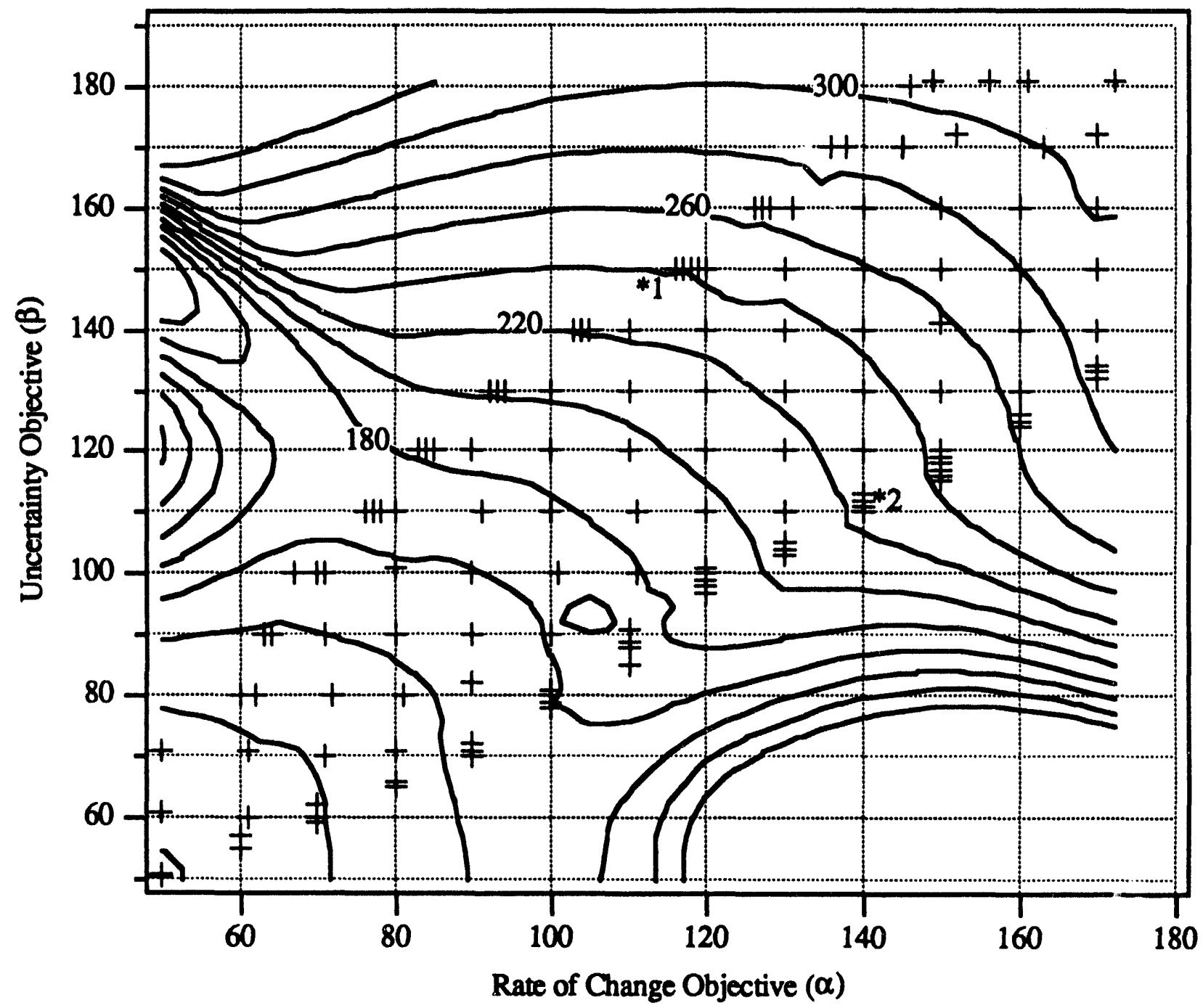

Figure 8. Contours of the Optimal Number of Samples Per Year as a Function of the Information Objectives - Includes Spatial Sampling Requirements (Asterisks indicate networks discussed in the text.)

constraints placed on the optimization model and of the narrow band within which the solutions lie. The two networks in Figure 8 are physically closer to one another (in objective function space) than the extreme networks $(* 1$ and $* 3)$ of Figure 4.

An obvious question that arises from the preceding examples is how the networks produced by the optimization model compare to the actual surveillance monitoring networks that have been used at the Hanford Site. Figure 11 is a network representative of the 1993 surveillance monitor- 


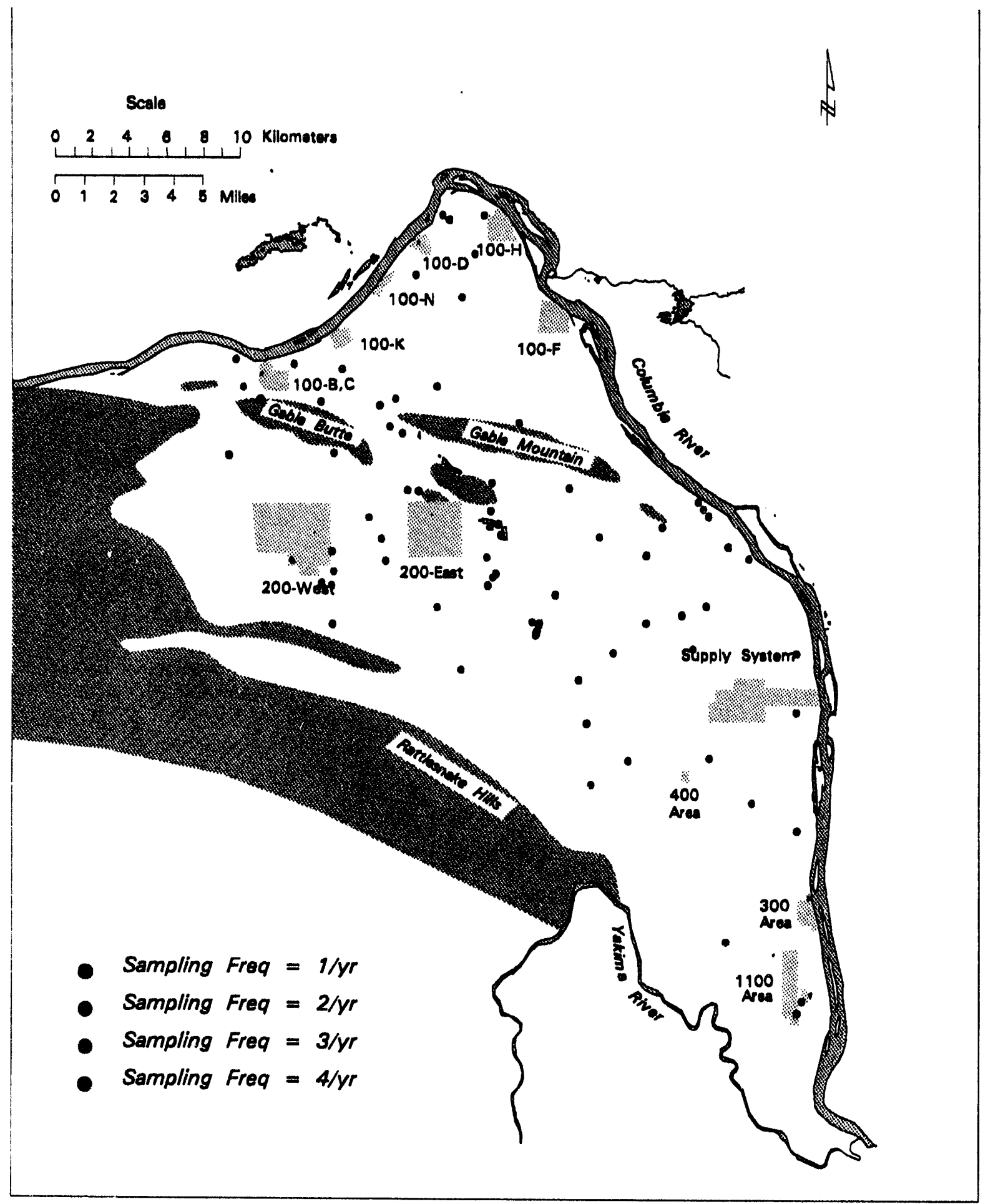

Figure 9. Optimal Network Solution Emphasizing the Uncertainty Objective $(* 1$ in Figure 8) - Includes Spatial Sampling Requirements. Network consists of 223 samples from 74 locations. 


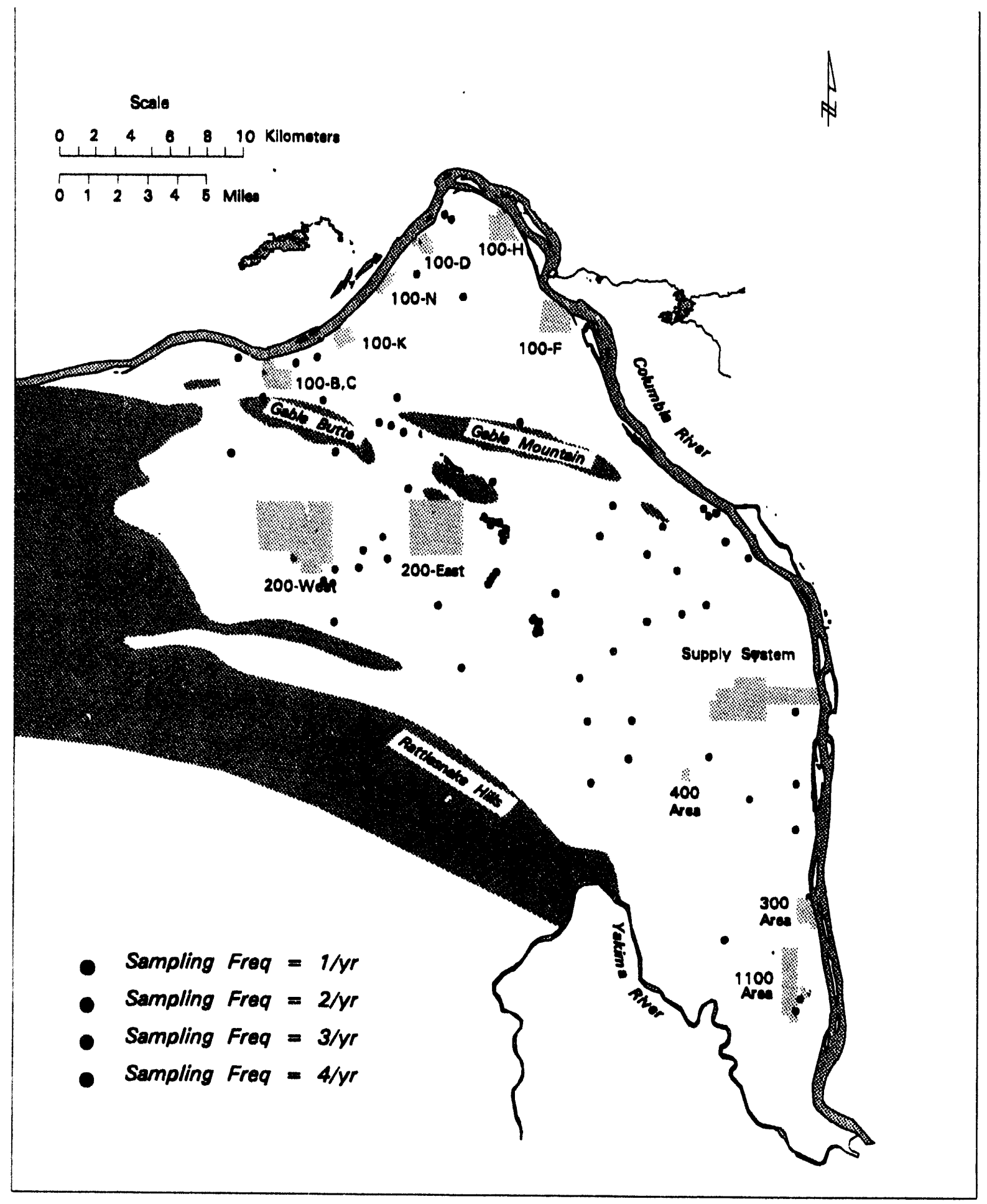

Figure 10. Optimal Network Solution Emphasizing the Concentration Change Objective $(* 2$ in Figure 8) - Includes Spatial Sampling Requirements. Network consists of 220 samples from 76 locations. 
ing network. ${ }^{(a)}$ The network consists of 264 samples from 163 locations. The complete network sampled 34 additional wells that did not appear in the subset of the database used to calculate the optimization model coefficients. These 34 wells are not included in Figure 11.

There were 15 wells in the network presented in Figure 11 that were to be used by the surveillance monitoring project, but that were being sampled for tritium by the RCRA or CERCLA monitoring programs. To provide a direct comparison, the optimization model was run with these 15 wells constrained to a sampling frequency of zero. The cost contours as a function of the information objectives are shown in Figure 12. Because the spatial sampling constraints were included, the contours are very similar to those of Figure 8. The additional constraints on the sampling frequencies of the 15 wells appear to increase the cost by approximately 10 samples for a given value of $\alpha$ and $\beta$. Two optimal networks with approximately the same number of samples as Figure 11 are indicated in Figure 12 and plotted in Figures 13 and 14. As before, these networks represent different emphasis on the two information objectives.

The position in objective space of the network of Figure 11 is also indicated in Figure 12. As measured with respect to these particular objectives, this network appears to be inferior. That is, for the same number of samples, the rate of change objective can be greatly increased without significantly reducing the uncertainty objective. The position of the network in objective space also seems to indicate that the uncertainty objective is much more important than the rate of change objective. A comparison of the three networks (Figures 11, 13, and 14), however, offers an altemative explanation for the apparent poor performance of the Figure 11 network.

Overall, the optimal networks have many wells in common with the network of Figure 11. The most striking difference in Figure 11 is the preponderance of wells that are sampled once or twice per year. The optimal networks tend to sample the majority of wells three or four times per year. (Note: $M I N S=1$ and $\gamma=2$ for this problem.) This is a consequence of the optimization model formulation and illustrates that an important network design consideration is missing from the model. Although the model may reveal the relative importance of sampling one well more frequently than another, the actual frequencies in the solutions may have little meaning. In all cases, in fact, a nearly optimal network can be found with a frequency of four samples per year at each well. For the network in Figure 14, such a network was found that requires only five additional

(a) J. C. Evans, Staff Scientist, Pacific Northwest Laboratory, personal conversation, March, 1993. 


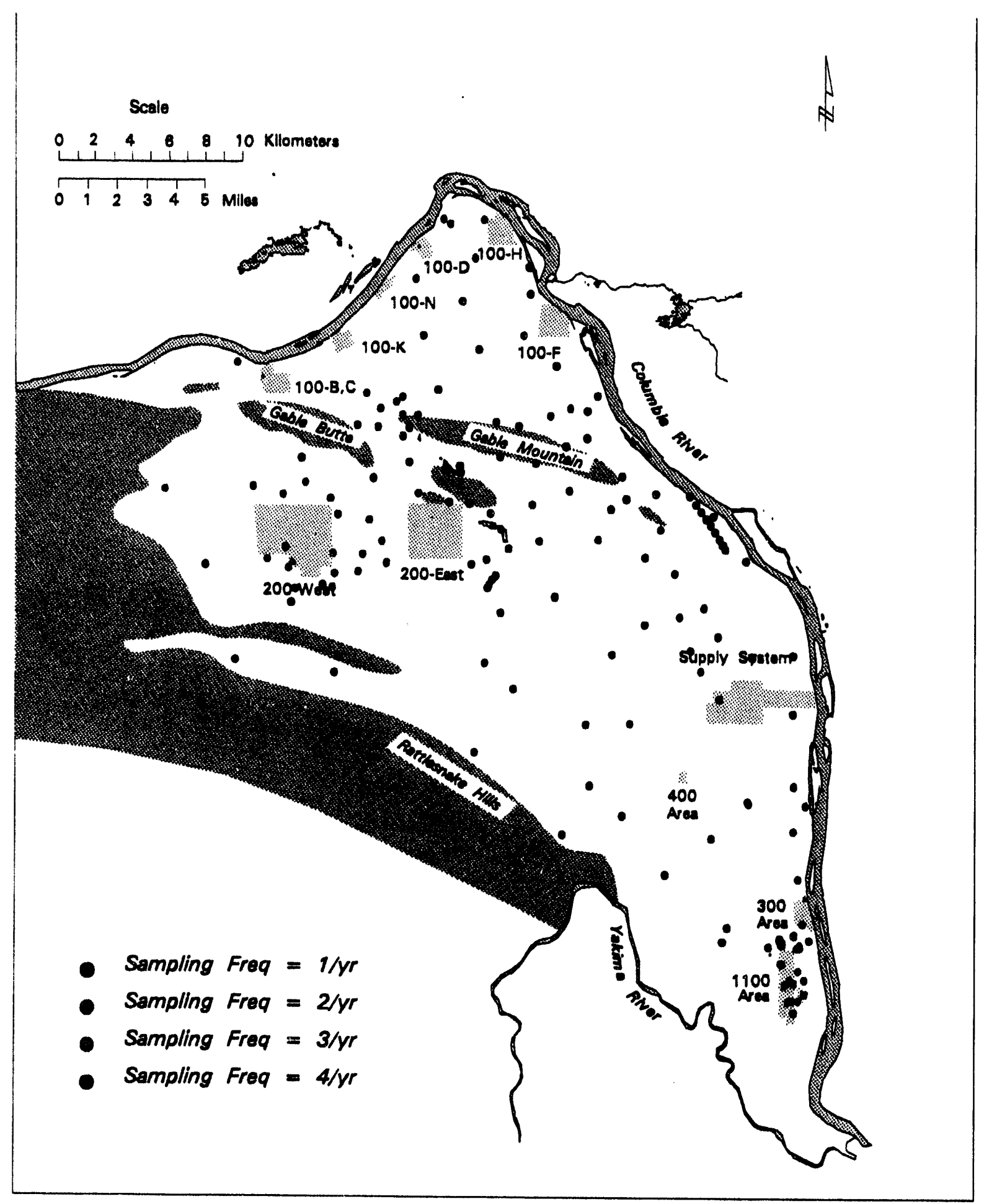

Figure 11. Representative Hanford Site Surveillance Monitoring Network Consisting of 264 Samples from 163 Locations 


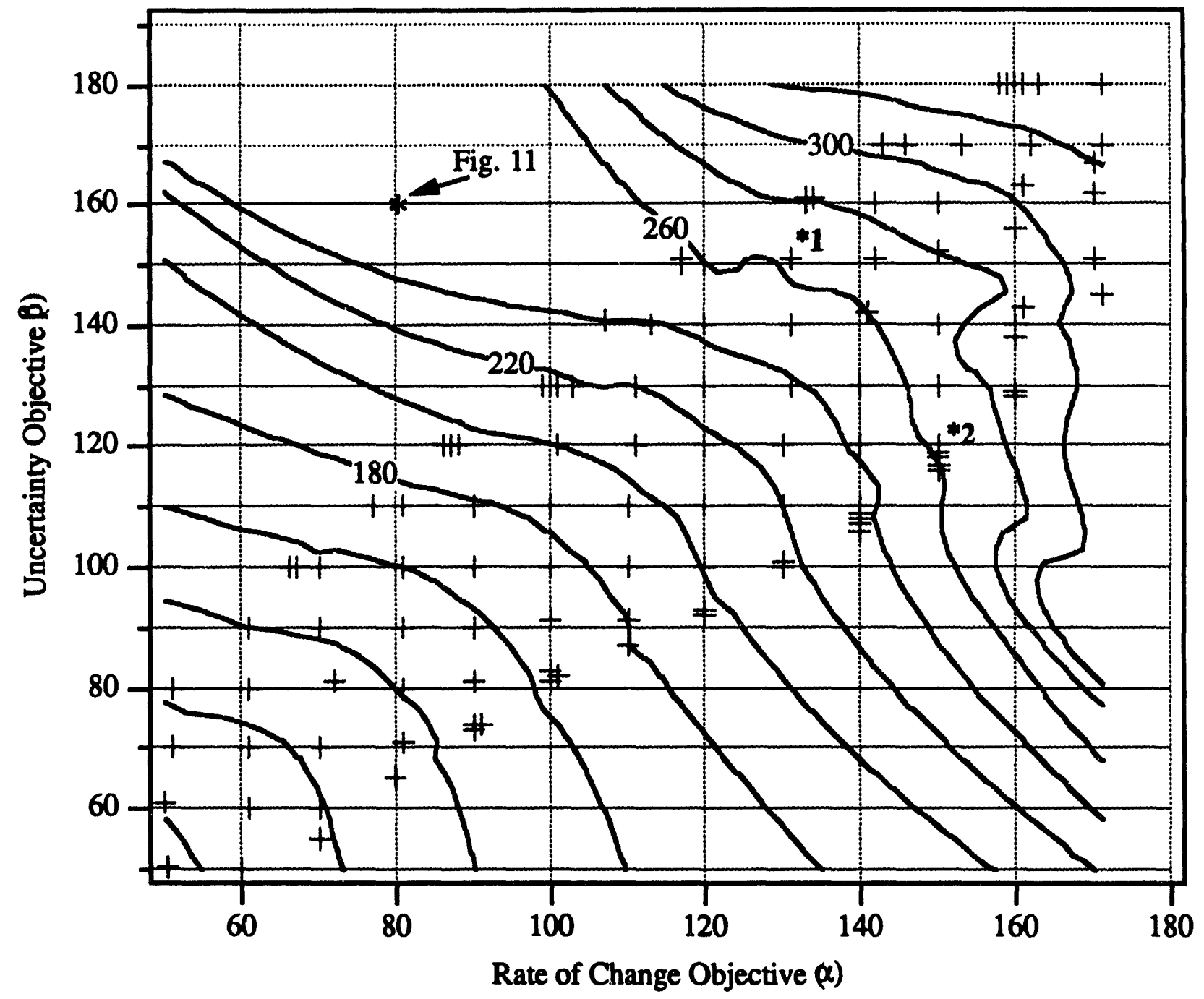

Figure 12. Contours of the Number of Samples as a Function of the Information Objectives - Includes Spatial Sampling Requirements. Fifteen well locations were constrained to have a sampling frequency of zero. (Asterisks indicate networks discussed in the text.)

samples to achieve the same values of the information objectives. This network samples 67 wells (compared to 84 in the network in Figure 14) four times per year. This result suggests that the model may be relatively insensitive to both sample location and frequency.

Many of the wells in Figure 11 are located in regions that are virtually unsampled by the optimal networks. In particular, the western boundary of the site is being sampled. This is not, however, the result of a miscalculation. These are background wells being sampled to determine 


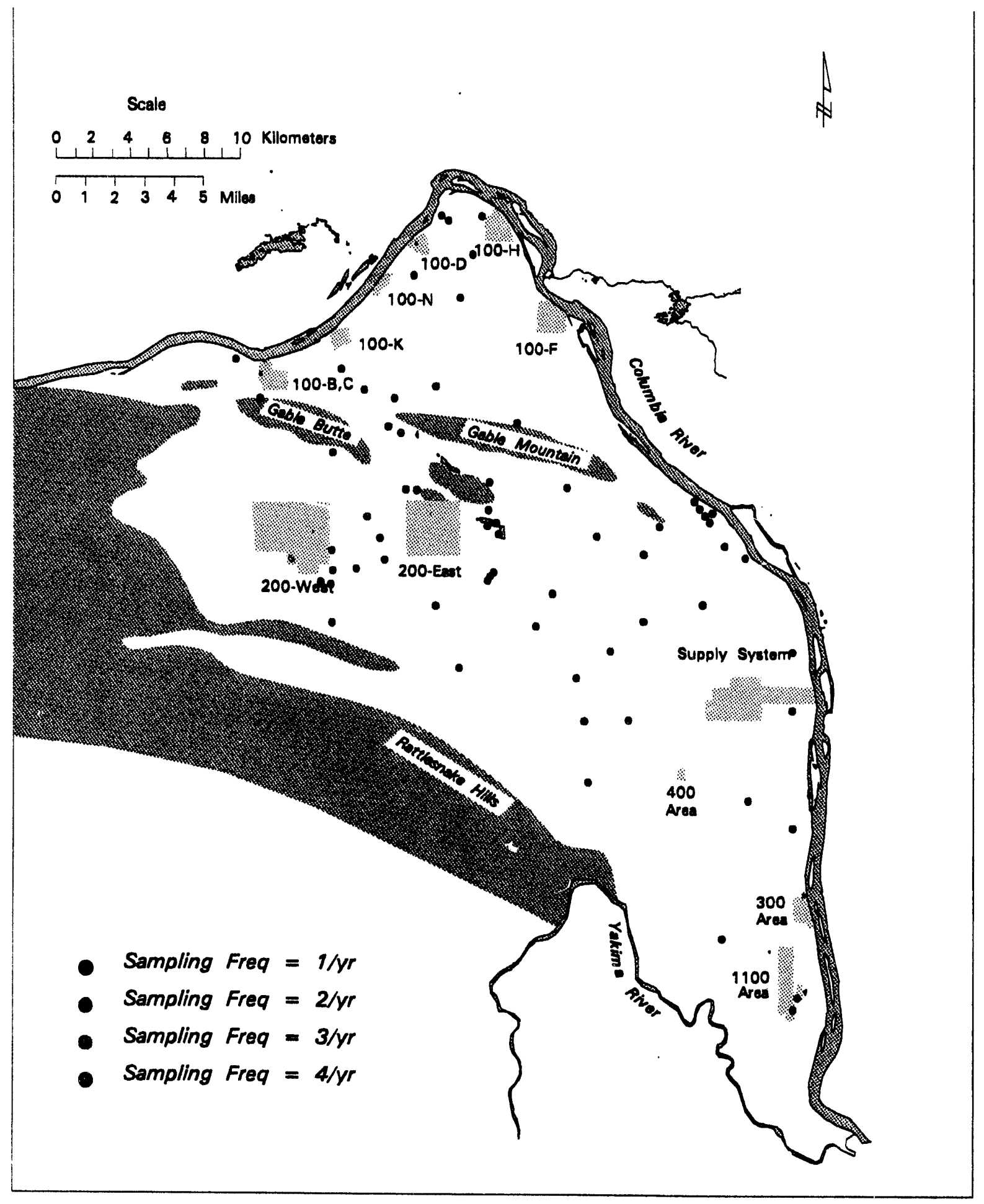

Figure 13. Optimal Network Solution Emphasizing the Concentration Change Objective $\left({ }^{*} 1\right.$ in Figure 12) - Includes Spatial Sampling Requirements. Network consists of 264 samples from 66 locations. 


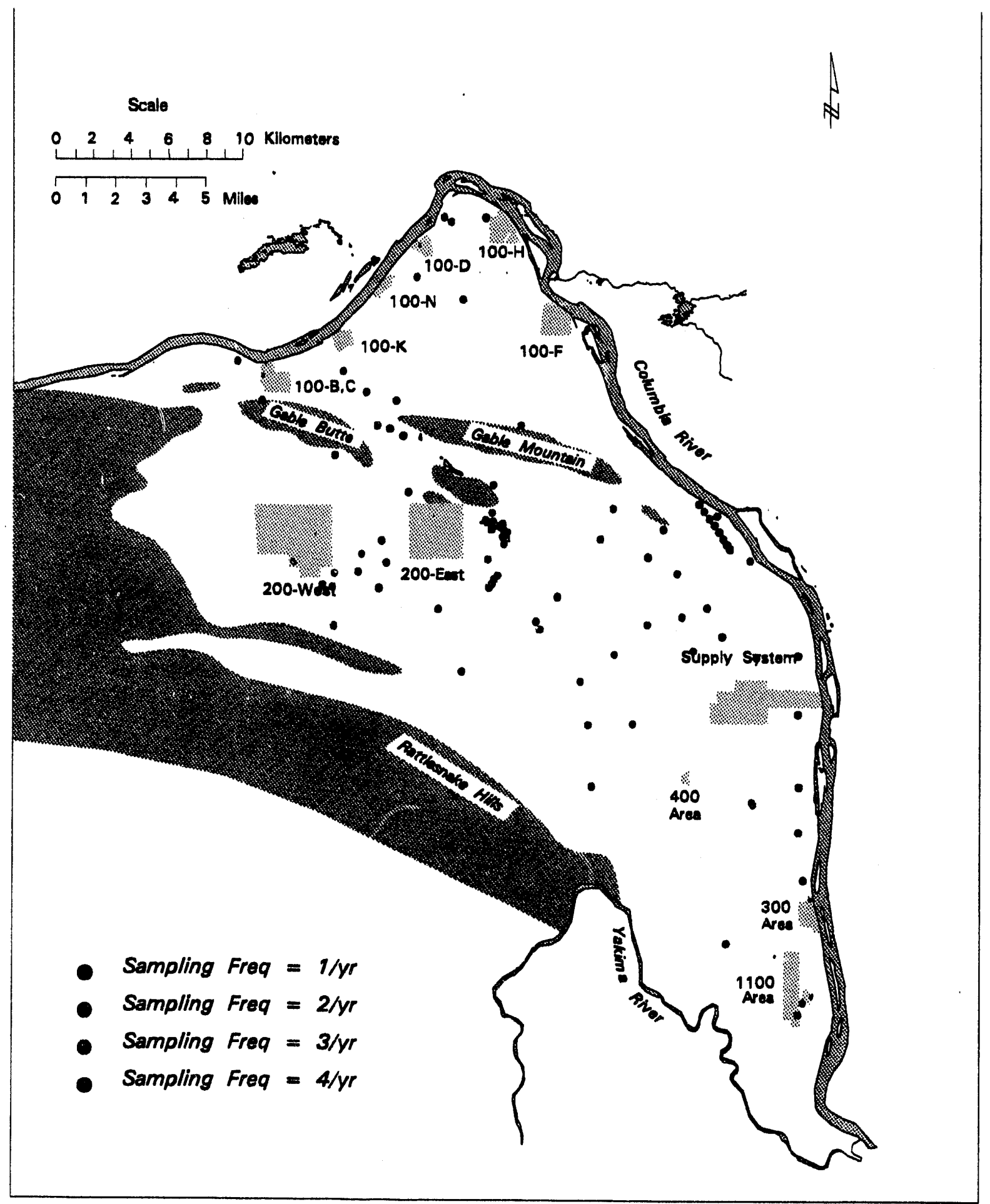

Figure 14. Optimal Network Solution Emphasizing the Concentration Change Objective (*2 in Figure 12) - Includes Spatial Sampling Requirements. Network consists of 259 samples from 84 locations. 
the condition of water moving onto the Site. Because this objective is not represented in the optimization model, one should not expect it to be reflected in the network solutions. Some of the wells north of the 200-West Area are also being sampled as background wells, although those closest to the Area are being sampled as part of plume monitoring. None of these wells appear in the optimization model results because the mean tritium concentration at each of these wells was determined to be less than $500 \mathrm{pCi} / \mathrm{L}$.

Other regions being sampled more heavily than the optimal networks represent are north and west of Gable Mountain, and the 300 and 1100 Areas. The Gable Mountain region is being heavily sampled because of the presence of tritium contamination in conjunction with a high degree of uncertainty about both the groundwater flowfield and the source of the contamination. This type of uncertainty is not represented in the optimization model. The 300 and 1100 Areas are being heavily sampled because of the presence of many contaminant sources and the proximity of water supply wells for the city of Richland. The optimization model does not represent the deep concern in preventing contamination of these drinking water supply wells.

The only region with a higher density of wells in the optimal networks than in the network of Figure 11 is near B Pond (see Figure 1 for the location of B Pond). The optimal network that emphasizes monitoring changes in concentration exhibits particularly dense sampling in this region. This is because of the discharge of tritium-contaminated water from B Pond (see Figure 1). 


\subsection{CONCLUSIONS}

The monitoring network design method developed in this report is applicable to surveillance monitoring of tritium contamination at the Hanford Site. The method generates network alternatives that minimize monitoring costs while attempting to maximize the amount of information the network generates. The information measures promote monitoring in regions of rapidly changing concentration and regions where the tritium concentration is highly uncertain.

Development and application of the method have revealed both strengths and weaknesses in the approach.

- The optimal networks generated by the design method have many wells in common with the surveillance monitoring networks being utilized on the Site. This indicates that the optimization model captures at least some of the important issues of the network design problem.

- There are also important differences between the networks generated by the model and the networks that have been used on the Site. Chief among these is the extensive monitoring of the 300 and 1100 Areas, which are virtually ignored by the network design method presented here. The reason these wells do not appear in any of the optimal solutions is that the mean concentration of these wells (as determined by the method described above) was less than the limit of $500 \mathrm{pCi} / \mathrm{L}$. The optimization model was thus not given the opportunity to include these wells in any network solution. In this case, there is clearly an important monitoring objective that is not captured in the network design method.

- The information objectives implemented in the method do not represent explicit quantities of concern. It is thus difficult to use the model to answer questions such as "How much information is given up by reducing the number of samples by one-third?" The model can best be used to compare networks.

- The definition of appropriate objectives that are both quantifiable and explicitly related to the decision maker's concerns is both the most crucial and the most difficult task in the application of quantitative network design methods. In the future, more effort should be dedicated to this task.

- A better spatial measure for determining the appropriate sampling density is needed. A method that relies on a geostatistical characterization of the contaminant concentration is one option. Such a method may incorporate models of groundwater flow and transport (Graham and McLaughlin 1989) or it may rely entirely on historical information (Graham and Tankersley 1993). A method of the first type may be capable of making more accurate long-term predictions of contaminant movement. The latter type of method is less computationally demanding and is particularly appropriate for surveillance monitoring at the Hanford Site because of the wealth of available data. 
- The optimization model presented here predicts that monitoring cost is relatively insensitive to the location and sampling frequency of monitoring wells. That is, network solutions can be found that look very different and have different values of the information objectives, but that have close to the same cost. Most optimal networks, however, have a number of wells in common. This indicates the existence of certain critical wells.

- Many constituents other than tritium are monitored as part of the Groundwater Surveillance Project. To be truly practical, the network design method should be extended to multiple constituents. 


\subsection{REFERENCES}

Andricevic, R. 1990. “Cost-Effective Network Design for Groundwater Flow Monitoring." Stochastic Hydrology and Hydraulics 4(1): 27-41.

Andricevic, R. 1993. "Coupled Withdrawal and Sampling Designs for Groundwater Supply Models." Water Resources Research 29(1): 5-16.

Bell, W. and S. Hillmer. 1987. Initializing the Kalman Filter in the Nonstationary Case. Research Report CENSUS/SRC/RR-87/33. Statistical Research Division, Bureau of the Census, Washington, D.C.

Box, G. E. P. and G. M. Jenkins. 1976. Time Series Analysis: Forecasting and Control. HoldenDay, Oakland, California.

Bryce, R. W., J. C. Evans, and K. B. Olsen. 1991. Ground-Water Sample Collection and Analysis Plan for the Ground-Water Surveillance Project. PNL-7872, Pacific Northwest Laboratory, Richland, Washington.

Cohon, J. L. 1978. Multiobjective Programming and Planning. Academic Press, New York.

Comprehensive, Environmental Response, Compensation and Liability Act (CERCLA) of 1980. 42 USC 9601, et seq., as amended.

DOE. See U.S. Department of Energy.

Evans, J. C., R. W. Bryce, and D. J. Bates. 1992. Hanford Site Ground-Water Monitoring for 1990. PNL-8073, Pacific Northwest Laboratory, Richland, Washington.

Graham, W. E. and D. McLaughlin. 1989. "Stochastic Analysis of Nonstationary Subsurface Solute Transport, 2. Conditional Moments." Water Resources Research 25(11): 2331-2355.

Graham, W. E., and C. D. Tankersley. 1993. "Forecasting Piezometric Head Levels in the Floridan Aquifer: A Kalman Filtering Approach." Water Resources Research 29(11): 3791-3800.

Haith, D. A. 1982. Environmental Systems Optimization. John Wiley \& Sons, New York.

Harvey, A. C. 1981. Time Series Models. John Wiley \& Sons, New York.

Jones, R. H. 1980. "Maximum Likelihood Fitting of ARMA Models to Time Series with Missing Observations." Technometrics 22: 389-395.

Kohn, R. and C. F. Ansley. 1986. "Estimation, Prediction, and Interpolation for ARIMA Models with Missing Data." Journal of the American Statistical Association 81: 751-761.

Loaiciga, H. A., R. J. Charbeneau, L. G. Everett, G. E. Fogg, B. F. Hobbs, and S. Rouhani. 1992. "Review of Ground-Water Quality Monitoring Network Design." ASCE Journal of Hydraulic Engineering 118(1): 11-37.

Marsten, R. E. 1981. "The Design of the XMP Linear Programming Library." ACM Transactions on Mathematical Software 7(4): 481-497.

Resource Conservation and Recovery Act (RCRA) of 1976. 42 USC 6901, et seq., as amended. 
Statistical Sciences, Inc. 1991. S-PLUS User's Manual. Statistical Sciences, Inc., Seattle. U.S. Department of Energy (DOE). 1988. Environment, Safety, and Health Directive. DOE Order 5400.1, U.S. Department of Energy, Washington, D.C. 


\section{Distribution}

No. of

Copies

OFESITE

10 DOE/Office of Scientific and

Technical Information

B. Blake

133 1st Avenue North

Minneapolis, MN 55401

2 Washington State Department of Health

Division of Radiation Protection

Building 5, M.S. L-13

Olympia, WA 98503
J. Erickson
G. Robertson

A. Danielson

Washington State Department of Health 1801 South 66th Ave.

Yakima, WA 98808

2 U. S. Geological Survey

1201 Pacific Ave., Suite 600

Tacoma, WA 98402

B. Drost

W. Lumm

3 Washington State Department of Ecology

99 South Sound Center

M.S. 7600

Olympia,WA $98504-7600$

D. Jansen

C. Cline

K. Kowalic
No. of

Copies

3 D. Nilander

Washington State Department of

Ecology

7601 W. Clearwater Avenue

Suite 102

Kennewick, WA 99336

R. Patt

Oregon State Department of

Water Resources

3850 Portland Road

Salem, OR 97310

Tom Gilmore

Confederated Tribes of the Umatilla

Indian Reservation

Department of Natural Resources

Hanford Projects

P.O. Box 638

Pendleton, OR 97801

ONSITE

22 DOE Richland Operations Office

G. M. Bell

J. K. Erickson

A5-52

M. J. Furman

A5-19

E. D. Goller

R3-80

J. D. Goodenough

A5-19

A. C. Harris

A5-19

R. D. Hildebrand (10)

A5-19

R. G. Holt

A5-55

R. G. McLeod

A5-15

P. M. Pak

A5-19

R. K. Stewart

A5-19

K. M. Thompson

A5-19

Public Reading Room

Dist.1 
PNL-8868

UC-600

No. of

No. of

Copies

Copies

2 U.S. Army Corps of Engineers

W. Greenwald

A5-20

C. Evans

K6-81

M. P. Johansen

A5-19

3 U.S. Environmental Protection

Agency

M. D. Freshley

K6-77

R. E. Gephart

K1-22

R. O. Gilbert

K7-34

T. J. Gilmore

K6-96

S. H. Hall

K6-96

M. S. Hanson

K1-51

P. T. Day

B5-01

R. E. Jaquish

K1-30

E. A. Jenne

K6-81

D. R. Sherwood (2)

B5-01

15 Westinghouse Hanford Company

M. R. Adams

H6-01

W. W. Laity

K2-50

G. V. Last

K6-96

P. E. Long

K6-84

S. P. Luttrell

K6-96

J. P. McDonald

K6-96

M. P. Connelly

H6-06

P. D. Meyer (10)

K6-77

J. J. Dorian

D. R. Newcomer

K6-96

K. R. Fecht

H6-30

K. B. Olsen

K6-81

L. C. Hulstrom

J. T. Rieger

K6-96

R. L. Jackson

H6-03

R. Schalla

K6-96

A. J. Knepp

H6-06

F. A. Spane, Jr.

K6-96

M. J. Lauterbach

H6-01

P. D. Thorne

K6-96

A. G. Law

H6-06

S. M. McKinney

T1-30

R. E. Peterson

H6-06

J. W. Roberts

H6-02

J. A. Serkowski

H6-06

L. C. Swanson

H6-06

S. E. Vukelich

H6-02

L. W. Vail

K6-77

W. D. Webber

K6-96

S. K. Wurstner

K6-77

Publishing Coordination

K1-06

Technical Report Files (5)

Routing

47 Pacific Northwest Laboratory

R. M. Ecker

SE-UI

M. J. Graham

K6-78

P. M. Irving

K6-98

M. P. Bergeron

K6-77

C. S. Sloane

K6-04

R. W. Bryce

K6-96

P. C. Hays (last)

K6-86

K6-96

K6-54

T. J. Carlson

K6-13

R. L. Dirkes

K6-81

P. E. Dresel

K6-11

Dist.2 

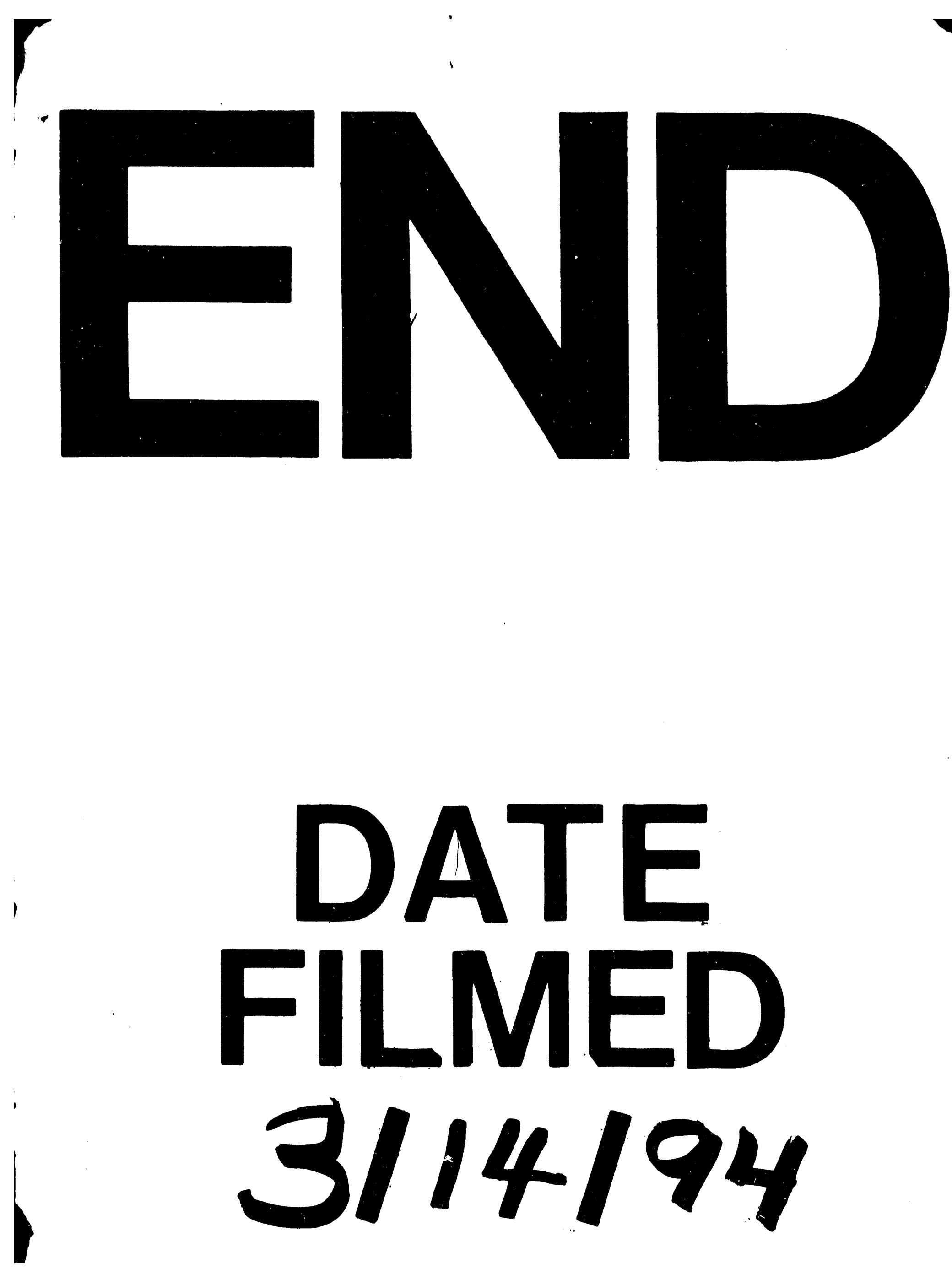
